\title{
Preclinical Advances in Theranostics for the Different Molecular Subtypes of Breast Cancer
}

\author{
Hanyi Fang ${ }^{1,2,3}$, Alessandra Cavaliere ${ }^{1}$, Ziqi Li $^{1,4}$, Yiyun Huang ${ }^{1}$ and \\ Bernadette Marquez-Nostra ${ }^{1 *}$
}

${ }^{1}$ PET Center, Department of Radiology and Biomedical Imaging, School of Medicine, Yale University, New Haven, CT, United States, ${ }^{2}$ Department of Nuclear Medicine, Union Hospital, Tongji Medical College, Huazhong University of Science and Technology, Wuhan, China, ${ }^{3}$ Hubei Province Key Laboratory of Molecular Imaging, Wuhan, China, ${ }^{4}$ Department of Nuclear Medicine, Tongji Hospital, Tongji Medical College, Huazhong University of Science and Technology, Wuhan, China

OPEN ACCESS

Edited by: Hong Shan,

Sun Yat-Sen University, China

Reviewed by:

Zibo Li,

University of North Carolina at Chapel Hill, United States

Bo Yu,

The Fifth Affiliated Hospital of Sun Yat-Sen University, China

${ }^{*}$ Correspondence: Bernadette Marquez-Nostra bernadette.marquez-nostra@ yale.edu

Specialty section:

This article was submitted to Pharmacology of Anti-Cancer Drugs, a section of the journal

Frontiers in Pharmacology

Received: 10 November 2020 Accepted: 22 February 2021

Published: 27 April 2021

Citation:

Fang H, Cavaliere A, Li Z, Huang Y and Marquez-Nostra B (2021) Preclinical Advances in Theranostics for the Different Molecular Subtypes of Breast Cancer.

Front. Pharmacol. 12:627693. doi: 10.3389/fphar.2021.627693
Breast cancer is the most common cancer in women worldwide. The heterogeneity of breast cancer and drug resistance to therapies make the diagnosis and treatment difficult. Molecular imaging methods with positron emission tomography (PET) and single-photon emission tomography (SPECT) provide useful tools to diagnose, predict, and monitor the response of therapy, contributing to precision medicine for breast cancer patients. Recently, many efforts have been made to find new targets for breast cancer therapy to overcome resistance to standard of care treatments, giving rise to new therapeutic agents to offer more options for patients with breast cancer. The combination of diagnostic and therapeutic strategies forms the foundation of theranostics. Some of these theranostic agents exhibit high potential to be translated to clinic. In this review, we highlight the most recent advances in theranostics of the different molecular subtypes of breast cancer in preclinical studies.

Keywords: theranostics (combined therapeutic and diagnostic technology), breast cancer subtypes, molecular imaging, targeted therapy, preclinical (in-vivo) studies, positron emission tomography, single-photon emission computed tomography

\section{INTRODUCTION}

The molecular subtypes of breast cancer are classified based on the status of estrogen receptor (ER), progesterone receptor (PR), and human epidermal growth factor receptor 2 (HER2). In addition to surgery, radiotherapy, and chemotherapy, the standard of care targeted treatments for breast cancer vary according to the molecular subtype of patient's tumor and stage of the disease. For ER-positive breast cancer, ER-targeting tamoxifen is the primary therapy for the non-metastastic luminal subtype of breast cancer (Masoud and Pagès, 2017). For HER2-positive breast cancer, monoclonal antibodies targeting this receptor, such as trastuzumab, have greatly improved the survival of breast cancer patients with non-metastatic disease (Waks and Winer, 2019). Finally, patients with advanced triple negative breast cancer are recently benefiting from immune therapy with the FDA-approval of the monoclonal antibody atezolizumab (Cyprian et al., 2019) or from the antibody drug conjugate, sacituzumab govitecan (Bardia et al., 2019).

However, patients with any breast cancer subtype can have intrinsic or acquired resistance to different therapeutics including chemotherapy, endocrine therapy, and targeted therapy (Chun et al., 2017). Further, tumor heterogeneity in the same patient presents a challenge for achieving complete and durable responses to targeted treatments (Steding, 2016; Blasco-Benito et al., 2018). To overcome resistance to standard of care treatments, many efforts have turned to combination therapies or addition of toxic payloads, such as 

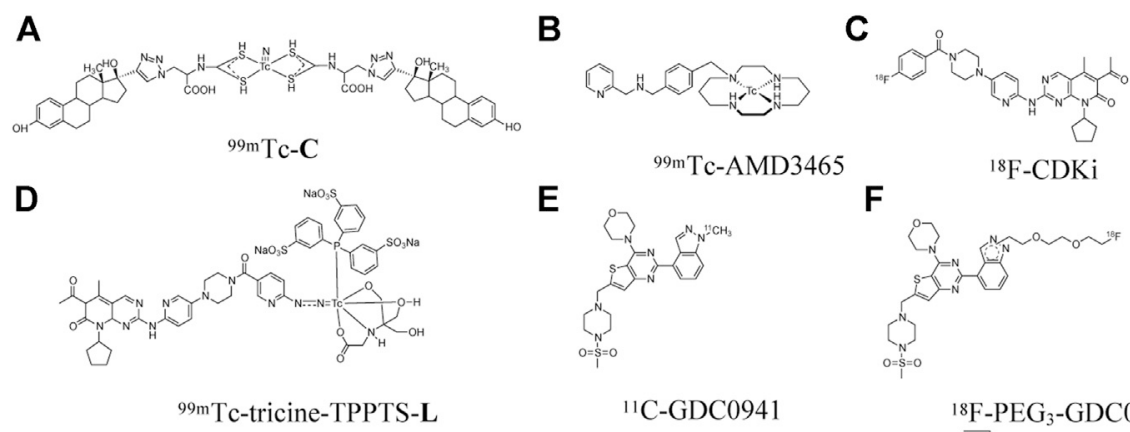

E

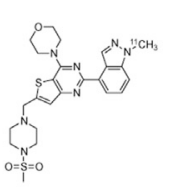

$\mathbf{F}$

${ }^{18} \mathrm{~F}-\mathrm{CDKi}$

G

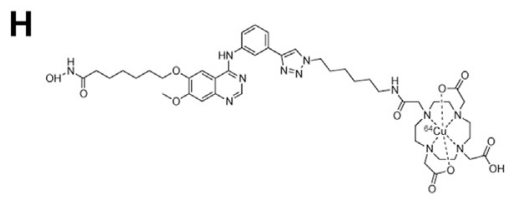

${ }^{11 C-G D C 0941}$
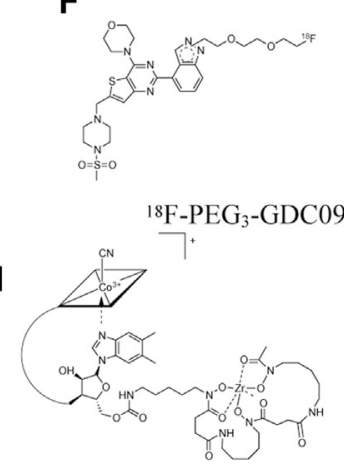

${ }^{124} \mathrm{I}-\mathrm{IPAG}$

${ }^{64} \mathrm{Cu}-\mathrm{HDACi}$

${ }^{89} \mathrm{Zr}-\mathrm{Cbl}$

FIGURE 1 | Structures of radiolabeled small molecules for imaging of breast cancer.

ionizing radiation, for targeted radionuclide therapy (TRT) (Lopez and Banerji, 2017). Many investigations have also been devoted to find new therapeutic targets closely associated with breast cancer aggressiveness, invasion, metastasis, and recurrence, such the gastrinreleasing peptide receptors (GRPR) overexpressed on the surface of cancer cells, cyclin-dependent kinase 4 and 6 (CDK4/6), histone deacetylase (HDACs), and MYC proto-oncogene. The availability of new targeted treatments for these targets prompted the development of non-invasive imaging agents via positron emission tomography (PET) or single-photon emission tomography (SPECT) to help select patients most likely to benefit from these treatments. The combination of diagnostic imaging and therapy forms the foundation of theranostics.

Currently, the diagnosis of breast cancer still depends on biopsy followed by tissue analysis using immunohistochemistry (IHC) or fluorescence in situ hybridization (FISH) to define receptor status and guide treatments. However, tissue analysis results may not be accurate due to several limitations, such as sampling errors, tumor heterogeneity, and changes in receptor status over the course of treatment (de Vries et al., 2019). Thus, non-invasive imaging of therapeutic targets or distribution of therapeutic agents throughout the whole body via PET or SPECT with radiolabeled agents can serve as a complementary diagnostic technique to tissue-based analyses. The type of imaging agent for nuclear imaging is also diverse and includes small molecules, peptides, antibodies, affibodies, antisense oligonucleotides, bispecific scaffolds, and nanoparticles. Figures 1, 2 show the diverse set of probes described in this review.

Herein, we highlight recent advances in preclinical imaging and targeted therapy, the combination of which form the basis of theranostics, for the different molecular subtypes of breast cancer. Table 1 lists the different imaging agents described in this review. We also draw attention to the different cell lines tested in preclinical

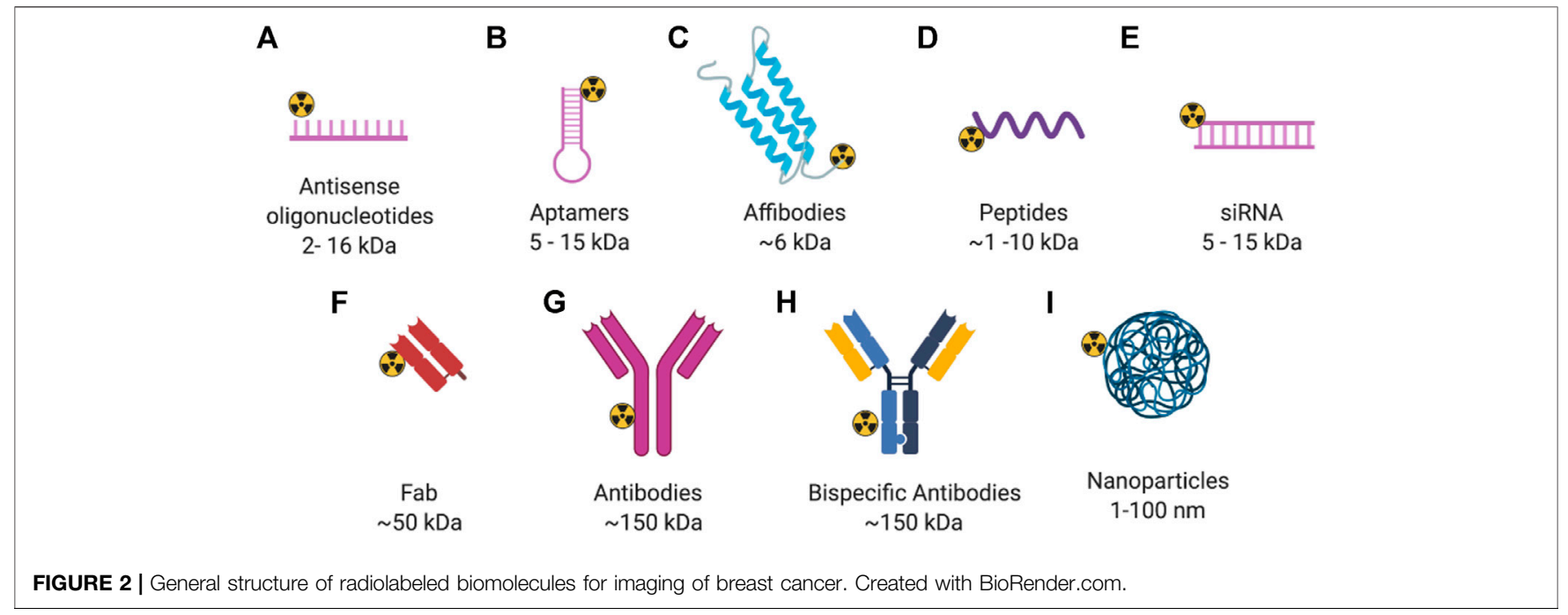


TABLE 1 | Summary of the preclinical imaging agents discussed in this review for the different subtypes of breast cancer.

\begin{tabular}{|c|c|c|c|c|c|}
\hline Target & Agent & $\begin{array}{l}\text { Type of } \\
\text { structure }\end{array}$ & Tumor model & $\begin{array}{l}\text { Imaging } \\
\text { modality }\end{array}$ & References \\
\hline \multicolumn{6}{|c|}{ Luminal-subtype } \\
\hline \multirow[t]{2}{*}{ ER } & ${ }^{99 m}$ Tc-DTPA-estradiol & Small molecule & MCF-7 & SPECT & Xia et al. (2016) \\
\hline & ${ }^{99 m} \mathrm{Tc}(\mathrm{V})$-nitrido complex $\mathbf{C}$ & Small molecule & MCF-7 & None & Tejería et al. (2019) \\
\hline CXCR4 & ${ }^{99 m}$ Tc-AMD3465 & Small molecule & MCF-7 & SPECT/CT & Zhang et al. (2018) \\
\hline GRPR & ${ }^{111}$ In-JMV4168 & Peptide & T47D & SPECT/CT & Dalm et al. (2015) \\
\hline \multirow[t]{3}{*}{ CDK4/6 } & ${ }^{18} \mathrm{~F}-\mathrm{CDKi}$ & Small molecule & MCF-7 & PET/CT & Ramos et al. (2020) \\
\hline & $\begin{array}{l}{ }^{99 m} \text { Tc-labeled palbociclib } \\
\text { analogs }\end{array}$ & Small molecule & MCF-7 & SPECT/CT & Song et al. (2019) \\
\hline & ${ }^{99 m}$ Tc-tricine-TPPTS-L & Small molecule & MCF-7 & SPECT/CT & Gan et al. (2020) \\
\hline \multirow[t]{2}{*}{ PI3K } & ${ }^{11} \mathrm{C}$-pictilisib (GDC-0941) & Small molecule & MCF-7 & PET & Han et al. (2019) \\
\hline & ${ }^{18} \mathrm{~F}_{-} \mathrm{PEG} \mathrm{G}_{3}-\mathrm{GDC}-0941$ & Small molecule & MCF-7 & PET & Altine et al. (2019) \\
\hline $\begin{array}{l}\text { Sigma-1 } \\
\text { receptor }\end{array}$ & ${ }^{124}$ I-IPAG & Small molecule & MCF-7 & PET & Gangangari et al. (2020) \\
\hline MDM2 & ${ }^{99 m}$ Tc-HYNIC-ASON & Antisense oligonucleotide & MCF-7 & SPECT & Fu et al. (2010) \\
\hline \multicolumn{6}{|l|}{ HER2-subtype } \\
\hline HER2 & ${ }^{18} \mathrm{~F}$-aptamer & Aptamer & BТ-474 & PET & Kim et al. (2019) \\
\hline HER3 & $\begin{array}{l}{ }^{111} \text { In-HEHEHE-Z08698- } \\
\text { NOTA }\end{array}$ & Affibody & BТ-474 & SPECT & Andersson et al. (2015) \\
\hline GRPR & ${ }^{68} \mathrm{Ga}-\mathrm{NOTA}-\mathrm{PEG}_{3}-\mathrm{RM} 26$ & Peptide & BT-474 & PET/CT & Varasteh et al. (2014) \\
\hline VPAC & ${ }^{68}$ Ga-NODAGA-peptide & Peptide & BT-474 & PET/CT & Kumar et al. (2019) \\
\hline Cobalamin (cbl) & ${ }^{89} \mathrm{Zr}-\mathrm{cbl}$ & Small molecule & MDA-MB-453 & PET & $\begin{array}{l}\text { Kuda-Wedagedara et al. } \\
(2017)\end{array}$ \\
\hline \multicolumn{6}{|c|}{ Triple-negative breast cancer } \\
\hline EGFR & ${ }^{99 m}$ Tc-PmFab-His6 & Fab & MDA-MB-468 & SPECT/CT & Ku et al. (2019a) \\
\hline CMKLR1 & ${ }^{68} \mathrm{Ga}-\mathrm{DOTA}-\mathrm{ADX}-\mathrm{CG} 34$ & Peptide & DU4475 & PET/MR & Erdmann et al. (2019) \\
\hline HDAC & ${ }^{64} \mathrm{Cu}-\mathrm{HDACi}$ & Small molecule & MDA-MB-231 & $\mathrm{PET} / \mathrm{CT}$ & Meng et al. (2013) \\
\hline MYC & ${ }^{89} \mathrm{Zr}$-transferrin & Protein & MDA-MB-231; MDA-MB-157 & PET & Henry et al. (2018) \\
\hline TF & ${ }^{64}$ Cu-NOTA-ALT-836-fab & Fab & MDA-MB-231 & PET & Shi et al. (2015) \\
\hline CXCR4 & ${ }^{99 m}$ Tc-HYNIC-siRNA1 & siRNA & MDA-MB-231 & SPECT & Fu et al. (2016) \\
\hline MUC1 & ${ }^{99 m}$ Tc-S1-apMUC1 & $\begin{array}{l}\text { Nanoparticle-aptamer } \\
\text { conjugate }\end{array}$ & MDA-MB-231 & SPECT & Pascual et al. (2017) \\
\hline \multicolumn{6}{|l|}{ Dual-receptor } \\
\hline \multirow[t]{2}{*}{ GRPR/FA } & ${ }^{99 m}$ Tc-BBN-FA & Bispecific peptide & T47D & SPECT/CT & Aranda-Lara et al. (2016a) \\
\hline & ${ }^{177}$ Lu-BBN-FA & Bispecific peptide & T47D & SPECT/CT & Aranda-lara et al. (2016b) \\
\hline $\begin{array}{l}\text { GRPR/ } \\
\operatorname{NPY}\left(Y_{1}\right) R\end{array}$ & ${ }^{68} \mathrm{Ga}-24$ & Bispecific peptide & $\mathrm{T} 47 \mathrm{D}$ & $\mathrm{PET} / \mathrm{CT}$ & Vall-Sagarra et al. (2018) \\
\hline$\alpha_{v} \beta_{3} / \mathrm{CD} 13$ & ${ }^{68} \mathrm{Ga}-N G R-R G D$ & Bispecific peptide & MCF-7 & PET/CT & Gai et al. (2020) \\
\hline EGFR/HER2 & $\begin{array}{l}{ }^{64} \text { Cu-NOTA-fab- } \\
\text { PEG24-EGF }\end{array}$ & Bispecific fab & MDA-MB-231-H2N & $\mathrm{PET} / \mathrm{CT}$ & Kwon et al. (2017) \\
\hline T-cell/CEA & ${ }^{89} \mathrm{Zr}-\mathrm{AMG} 211$ & Bispecific antibody & BT-474 & PET & Waaijer et al. (2018) \\
\hline EGFR/c-MET & {$\left[{ }^{89} \mathrm{Zr}\right] \mathrm{ZrDFO}$-amivantamab } & Bispecific antibody & $\begin{array}{l}\text { MDA-MB-468; MDA-MB-231; } \\
\text { MDA-MB-453 }\end{array}$ & $\mathrm{PET} / \mathrm{CT}$ & Cavaliere et al. (2020) \\
\hline
\end{tabular}

studies, which represent each molecular subtype of breast cancer to help guide future investigations of novel theranostic agents.

\section{PRECLINICAL IMAGING AGENTS FOR THE DIFFERENT SUBTYPES OF BREAST CANCER}

\section{Luminal Subtype}

The luminal subtype of breast cancer accounts for about $70 \%$ of all breast cancer patients and encompasses molecular signatures that are
ER and/or PR positive, and HER2 negative (Waks and Winer, 2019). As the luminal subtype is the most common subtype of breast cancer, many research efforts have been focused on cell surface receptors and intracellular targets for development of both molecular imaging and targeted therapy of luminal breast cancer. Summarized below are some of the most promising agents for PET and SPECT imaging of the luminal subtype of breast cancer.

\section{Cell Surface Receptor}

Approximately $70 \%$ of breast cancers express ER or PR, or both. Hence, endocrine therapy is the most important treatment for the 
luminal subtype of breast cancer. Imaging of ER and PR can help determine the status of the tumor tissue, and thus predict prognosis and efficacy of endocrine therapy. A recent review highlighted the preclinical and clinical research progress within the last 5 years of ER imaging with ${ }^{18} \mathrm{~F}$-fluoroestradiol $\left({ }^{18} \mathrm{~F}\right.$-FES) and $\mathrm{PR}$ imaging with ${ }^{18} \mathrm{~F}$-fluorofuranyl norprogesterone $\left({ }^{18}\right.$ F-FFNP) in breast cancer (Kumar et al., 2020). Here, we summarized some promising studies that showed imaging of other targets in breast cancer luminal subtype xenografts.

Typically, the MCF-7 and T47D xenograft models are used as high ER-expressing animal models while the MDA-MB-231 xenograft is used as a low ER-expressing model in many of the studies that we summarize herein (Dai et al., 2017). One SPECT imaging agent for ER is an estradiol analog labeled with ${ }^{99} \mathrm{~m}_{\mathrm{Tc}}\left(\mathrm{t}_{1 / 2}=6 \mathrm{~h}\right)$ using diethylenetriamine pentaacetate (DTPA) as the chelate to afford ${ }^{99 \mathrm{~m}}$ Tc-DTPA-estradiol (Xia et al., 2016). High tumor uptake was found in MCF-7 xenografts with $6.1 \pm$ $0.38 \% \mathrm{ID} / \mathrm{g}$ at $4 \mathrm{~h}$ post-injection (p.i.), and high tumor-toblood $(\mathrm{T} / \mathrm{B})$ ratio of $2.8 \pm 0.39$. As expected, low tumor uptake was observed in the MDA-MB-231 xenografts. Nonetheless, high uptake that amounted to $50 \% \mathrm{ID} / \mathrm{g}$ at $4 \mathrm{~h} \mathrm{p}$. i. in the liver, which is a common site for metastasis of breast tumor (Ma et al., 2015), may limit the detection of metastatic lesions in this organ when ${ }^{99 \mathrm{~m}} \mathrm{Tc}$-DTPA-estradiol is translated to clinical studies. Another derivative of estradiol, ${ }^{99 \mathrm{~m}} \mathrm{Tc}(\mathrm{V})$-nitrido complex C ( ${ }^{99 \mathrm{~m}} \mathrm{Tc}-\mathrm{C}$, Figure 1), was also developed for SPECT imaging of ER (Tejería et al., 2019). Uptake of ${ }^{99 \mathrm{~m}} \mathrm{Tc}-\mathrm{C}$ in the liver, at $1.1 \pm 0.38 \% \mathrm{ID} / \mathrm{g}$ at $2 \mathrm{~h} \mathrm{p}$. i., was much lower than that of ${ }^{99 \mathrm{~m}}$ Tc-DTPA-estradiol. However, its tumor uptake was also very low $(0.59 \pm 0.12 \% \mathrm{ID} / \mathrm{g})$, which resulted in a low $\mathrm{T} / \mathrm{B}$ ratio of only $0.35 \pm 0.19$ at $1 \mathrm{~h}$ p. i., i.e., lower concentration in tumor tissue than blood. Differences in tumor uptake of these two estradiolderived probes might be due to their different chemical structures that can affect pharmacokinetic properties and receptor-binding specificity. Hence, further optimization is still needed to improve ER targeting and pharmacokinetic properties and provide better contrast between metastatic lesions and surrounding normal tissue.

The chemokine receptor 4 (CXCR4), a seven-transmembrane $\mathrm{G}$ protein-coupled receptor (GPCR), is another promising target for theranostic development (Kircher et al., 2018). CXCR4 is expressed in $67 \%$ of breast cancer cells, with a level double of that in normal breast tissues (Salvucci et al., 2006). Several studies demonstrated that CXCR4 expression may have value in predicting breast cancer prognosis (Xu et al., 2015). For examples, breast cancer patients with high levels of CXCR4 were found to have more extensive metastasis to lymph nodes (Kato et al., 2003) and significantly reduced disease-free survival and overall survival (Zhang et al., 2014a). There are several CXCR4 inhibitors under clinical trials for the treatment of multiple myeloma, small cell lung cancer, and leukemia (Cooper et al., 2017; Salgia et al., 2017; Ghobrial et al., 2019), although none has been reported for breast cancer. AMD3465, a small molecule antagonist of CXCR4, was labeled with ${ }^{99 \mathrm{~m}} \mathrm{Tc}$ to obtain ${ }^{99 \mathrm{~m}} \mathrm{Tc}$-AMD3465 (Figure 1) (Zhang et al., 2018). It showed a moderate tumor uptake of $2.1 \pm 0.39 \% \mathrm{ID} / \mathrm{g}$, but high $\mathrm{T} / \mathrm{B}$ ratio of 9.4 at $1 \mathrm{~h}$ p. i. Specific binding of ${ }^{99 \mathrm{~m}} \mathrm{Tc}$ -
AMD3465 to CXCR4 was demonstrated by treatment with excess unlabeled AMD3465 which reduced tumor uptake by $36 \%$.

Another example of a cell surface receptor is the gastrinreleasing peptide receptor (GRPR), which is a G-protein coupled receptor highly expressed in the pancreas and lowly expressed in the normal breast tissues (Baratto et al., 2020). In autoradiography studies, GRPR was reported to be expressed at high density ( $>2000 \mathrm{dpm} / \mathrm{mg}$ tissue) in $74 \%$ (50 of 68 ) of breast cancer tissues from patients (Reubi et al., 2002).

Evaluating radiotracers that bind to GRPR typically employ the T47D xenograft model, as this cell line express high levels of GRPR. Agonists and antagonists of GRPR have been adapted as

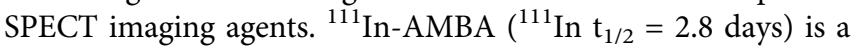
GRPR agonist that has been tested in an autoradiography study of 50 human breast cancer tissue specimens, with $96 \%(48 / 50)$ of them showing elevated GRPR levels (Dalm et al., 2015). A positive correlation was also found between ER status and GRPR expression. Those results were in agreement with previous studies, where a positive correlation between ER expression and GRPR binding affinity was detected in human breast cancer samples (Halmos et al., 1995). ${ }^{111}$ In-JMV4168 (Peptides, Figure 2), a GRPR antagonist, was developed for SPECT/CT imaging (Dalm et al., 2015). Tumor uptake was about $5 \% \mathrm{ID} / \mathrm{g}$ in both subcutaneous and orthotopic tumors of T47D xenografts (Figure 3). Autoradiography showed high binding of ${ }^{111}$ In-JMV4168 in T47D xenografts. In orthotopic tumor tissues, ${ }^{111}$ In-JMV4168 bound with $2.2 \pm 4 \%$ of added dose (\%AD), whereas low binding was observed in the blocking group with $0.1 \% \mathrm{AD}$, confirming the specific binding of ${ }^{111}$ In-JMV4168 to GRPR ex vivo (Dalm et al., 2015).

\section{Intracellular Targets}

Cell cycle dysregulation leads to uncontrolled progression to tumor (Schafer, 1998). The cell cycle consists of 4 phases: DNA replication $(\mathrm{S})$, mitosis $(\mathrm{M})$, and two gaps (G1 and $\mathrm{G} 2$ )

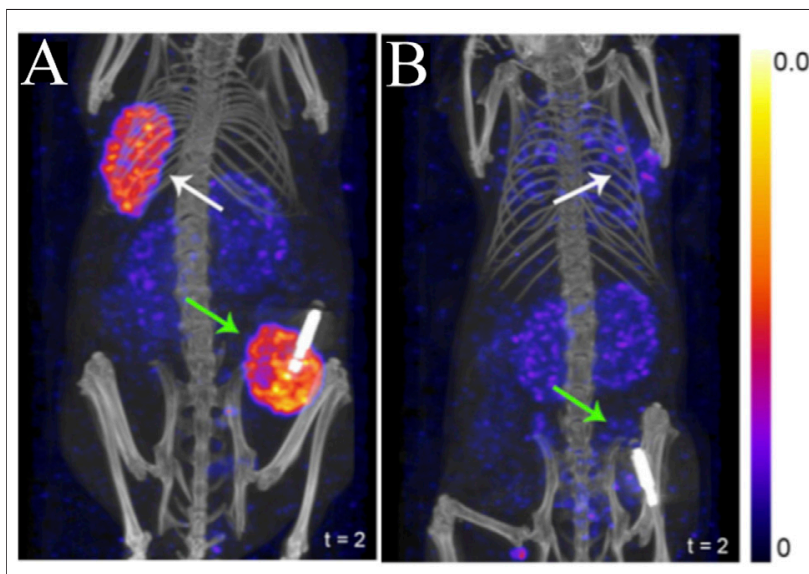

FIGURE 3 | SPECT/CT imaging using ${ }^{111}$ In-JMV4168 in orthotopic (green arrows) and subcutaneous (white arrows) tumors of T47D (A) and MCF7 (B) xenografts at $4 \mathrm{~h}$ post-injection of ${ }^{111}$ In-JMV4168 (Dalm et al., 2015). The general structure of ${ }^{111}$ In-JMV4168 was shown in

Figure 2D. 
between the $\mathrm{S}$ and $\mathrm{M}$ phases. Cyclin-dependent kinases 4/6 (CDK4/6) are two kinases that control cell cycle from G1 to S phase (Lee et al., 2019). CDK4/6 overexpression occurs in many cancers, including breast cancer (O'Sullivan et al., 2019; VanArsdale et al., 2015). Palbociclib, a CDK4/6 inhibitor (CDKi), is in phase 3 clinical trials for the treatment of ERpositive advanced breast cancer (Finn et al., 2016). The use of radiolabeled CDKi for tumor imaging has gained increased attention as companion diagnostic imaging agents to these inhibitors. The palbociclib CDKi was labeled with ${ }^{18} \mathrm{~F}\left(\mathrm{t}_{1 / 2}=\right.$ $110 \mathrm{~min}$ ) to obtain ${ }^{18} \mathrm{~F}$-CDKi (Figure 1), for PET imaging of MCF-7 xenografts (Ramos et al., 2020). Tumor uptake was high at about $4 \% \mathrm{ID} / \mathrm{g}$ at $2 \mathrm{~h}$ p. i for ${ }^{18} \mathrm{~F}-\mathrm{CDKi}$, which translated into a high $\mathrm{T} / \mathrm{B}$ ratio of about 5 . The tumor uptake decreased to $0.3 \% \mathrm{ID} / \mathrm{g}$ at $2 \mathrm{~h}$ p. i. when mice were blocked with excess of palbociclib.

A series of ${ }^{99 \mathrm{~m}} \mathrm{Tc}$-labeled palbociclib analogs were also developed for SPECT imaging (Song et al., 2019). However, tumor uptake was moderate, and T/B ratios were low for the ligand series, accompanied by very high liver uptake of more than $50 \% \mathrm{ID} / \mathrm{g}$. In this study, ${ }^{99 \mathrm{~m}} \mathrm{Tc}-\mathrm{L} 2$ showed the highest tumor uptake of $2.7 \pm 0.26 \% \mathrm{ID} / \mathrm{g}$ but low T/B ratio of 0.42 at $2 \mathrm{~h}$ p. i. However, the highest radiotracer accumulation was observed in the liver of greater than $50 \% \mathrm{ID} / \mathrm{g}$ from ${ }^{99 \mathrm{~m}} \mathrm{Tc}-\mathrm{L} 2$ to L5, which might be due to their relatively high lipophilicity $(\log P=1.5)$. To reduce the liver uptake, the chelator was changed from an isocyano-group to an hydrazinonicotinamide (HYNIC) moiety, where tricine/TPPTS were used as co-ligands to afford a new ${ }^{99} \mathrm{~m}$ Tc-labeled palbociclib complex, ${ }^{99 \mathrm{~m}}$ Tc-tricine-TPPTS-L (Figure 1) (Gan et al., 2020). The Log $P$ of the ${ }^{99 \mathrm{~m}}$ Tc-tricineTPPTS-L variant was $-2.9 \pm 0.1$, which was much lower than that of ${ }^{99 \mathrm{~m}} \mathrm{Tc}-\mathrm{L} 2$ to $\mathrm{L} 5$, demonstrating that ${ }^{99 \mathrm{~m}} \mathrm{Tc}$-tricine-TPPTS-L was more hydrophilic. Tumor uptake of ${ }^{99 \mathrm{~m}} \mathrm{Tc}$-tricine-TPPTS-L was good, at $3.8 \pm 1.3$ and $2.7 \pm 0.58 \% \mathrm{ID} / \mathrm{g}$ at 1 and $2 \mathrm{~h}$ p. i., respectively, albeit with low $\mathrm{T} / \mathrm{B}$ ratio of about 0.4 . The liver uptake was indeed much reduced to as low as $4.2 \pm 0.33 \% \mathrm{ID} / \mathrm{g}$ at $2 \mathrm{~h}$ p. i. These studies showed that radiolabeled palbociclib analogs may have the potential to image CDK4/6 via PET or SPECT as a companion diagnostic agent to CDK4/6 inhibitors.

Another intracellular kinase that also regulates cell proliferation, survival, and migration is the phosphatidylinositol 3-kinase (PI3K) (Bader et al., 2005). Abnormal activation of PI3K/Akt/mTOR has been found in about $70 \%$ of breast cancer cases (Cancer-Genome-AtlasNetwork, 2012). Pictilisib (GDC-0941), a PI3K inhibitor, is currently under phase $\mathrm{Ib}$ clinical trial in patients with advanced breast cancer and non-small cell lung cancer (Yamamoto et al., 2017; Schöffski et al., 2018). Pictilisib was labeled with ${ }^{11} \mathrm{C}\left(\mathrm{t}_{1 / 2}=20 \mathrm{~min}\right)$ for PET imaging in pictilisibsensitive MCF-7 xenograft models (Han et al., 2019). The tumor uptake of ${ }^{11} \mathrm{C}$-pictilisib was $2.9 \pm 0.07 \% \mathrm{ID} / \mathrm{g}$ with $\mathrm{T} / \mathrm{B}$ ratio of $2.1 \pm 0.34$ at $1 \mathrm{~h}$ p. i. in these xenograft models, demonstrating excellent tumor penetration regardless of the short half-life of ${ }^{11} \mathrm{C}$. In contrast, $\mathrm{PET}$ imaging with ${ }^{11} \mathrm{C}$-pictilisib in pictilisib-resistant MDA-MB-231 xenograft models showed significantly decreased tumor uptake. However, uptake in the liver was the highest. To reduce liver uptake, a triethylene glycol di ( $p$-toluenesulfonate)

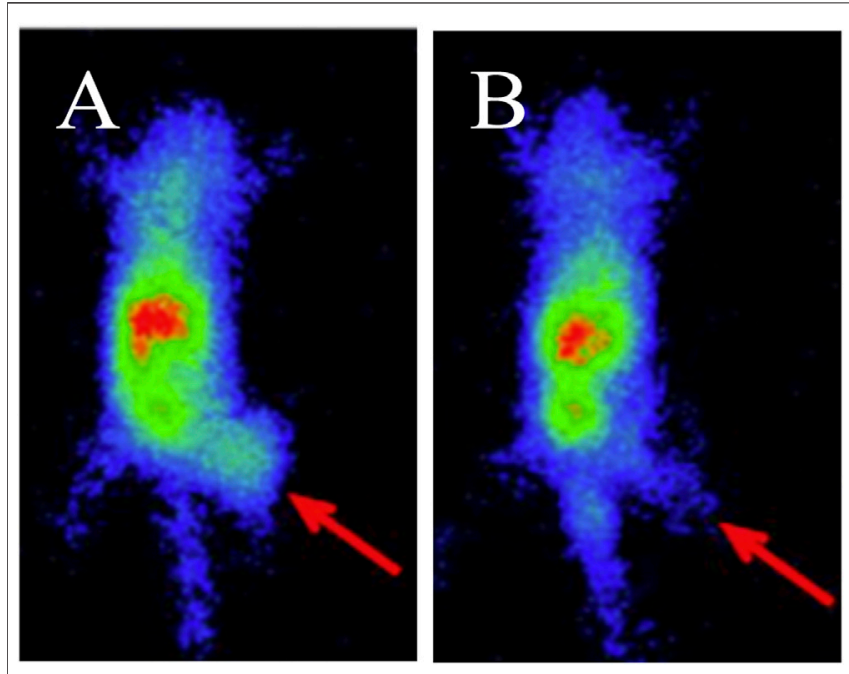

FIGURE 4 | SPECT Imaging of MDM2 expression in MCF-7 xenografts using ${ }^{99 \mathrm{~m}} \mathrm{TC}-\mathrm{HYNIC}$-antisense (A) and mismatch (B) probes at $4 \mathrm{~h}$ postinjection. Tumors are indicated by red arrows (Fu et al., 2010). The general structure of ${ }^{99 \mathrm{~m}} \mathrm{Tc}-\mathrm{HYNIC}$-antisense was shown in Figure 2A.

(TsO-PEG ${ }_{3}$-OTs) modified agent, ${ }^{18} \mathrm{~F}_{-} \mathrm{PEG}_{3}$-GDC-0941, was developed (Altine et al., 2019). Its liver uptake was $4.7 \pm 0.86$ $\% \mathrm{ID} / \mathrm{g}$ at $1 \mathrm{~h} \mathrm{p}$. i., which is about $76 \%$ lower than that of ${ }^{11} \mathrm{C}$-pictilisib. ${ }^{18} \mathrm{~F}-\mathrm{PEG}_{3}-\mathrm{GDC}-0941$ also showed high and specific tumor uptake, indicating that imaging PI3K could be a potential strategy for monitoring response to pictilisib treatment.

Sigma-1 receptors (S1R) is a unique ligand-regulated membrane protein involved in modulating cellular protein and lipid homeostasis (Maher et al., 2018). S1R mRNA was found to be overexpressed in $64 \%$ of breast cancer tissues, and in several ER-positive breast cancer cell lines on the cell membrane and in the endoplasmic reticulum (Wang et al., 2004). The small molecule inhibitor of S1R 1-(4-Iodophenyl)-3-(2-adamantyl) guanidine (IPAG) was shown to decrease the expression of the programmed death receptor ligand 1 (PD-L1) and suppress PD$\mathrm{L} 1$ interaction with its $\mathrm{PD}-1$ receptor in T-cell, and in cell lines of PC3 prostate cancer and MDA-MB-231 triple negative breast cancer (Maher et al., 2018). IPAG was labeled with ${ }^{124} \mathrm{I}\left(\mathrm{t}_{1 / 2}=4.18\right.$ days) (Figure 1) for PET imaging in MCF-7 xenografts (Gangangari et al., 2020). The tumor uptake of ${ }^{124} \mathrm{I}-\mathrm{IPAG}$ was $1.1 \pm 0.24$ and $0.94 \pm 0.22 \% \mathrm{ID} / \mathrm{g}$ at 24 and $48 \mathrm{~h}$ p. i., respectively, with extremely high $\mathrm{T} / \mathrm{B}$ ratio of $22 \pm 6.6$ and $46 \pm 10.0$. With the specific targeting and the high T/B ratios, ${ }^{124} \mathrm{I}-\mathrm{IPAG}$ holds great potential for imaging S1R in tumor and may be used to help to define the interaction between S1R and PD-L1 as a consequence of S1R-targeted or checkpoint inhibitor therapy.

Apart from protein targets, oncogenes are also attractive targets in breast cancer. Mouse double-minute 2 (MDM2), an oncogene, is regarded as the major negative regulator of the function of the p53 tumor suppressor, and found to be overexpressed in many malignant tumors, including breast cancer (Haupt et al., 2017). High expression of MDM2 with the consequent inactivating of p53 is associated with tumor development (Graat et al., 2007, Zhang et al., 2017). The 
${ }^{99 \mathrm{~m}}$ Tc-labeled antisense oligonucleotides (ASONs) (Antisense oligonucleotides, Figure 2) has been used to visualize MDM2 mRNA expression in MCF-7 xenografts through SPECT imaging (Figure 4) (Fu et al., 2010). This antisense probe and its mismatched oligonucleotide control have similar biodistribution properties in normal organs with fast blood clearance. The tumor uptake of the probe was high and steady from $9.2 \pm 1.4$ to $8.1 \pm 1.1 \% \mathrm{ID} / \mathrm{g}$ at 1 and $6 \mathrm{~h} \mathrm{p}$. i., respectively, with increasing $\mathrm{T} / \mathrm{B}$ ratio of 1.24 at $1 \mathrm{~h}$ p. i. to 4.11 at $6 \mathrm{~h}$ p. i.. In contrast, tumor uptake of the mismatched oligonucleotide control was significantly lower. This study demonstrates the feasibility of specifically targeting MDM2 mRNA with ${ }^{99} \mathrm{~m}$ TcHYNIC-ASON. With increasing evidence showing that antisense oligonucleotides contribute to breast cancer treatment (Yang et al., 2003), in vivo imaging with radiolabeled antisense oligonucleotides may provide a tool to monitor therapeutic response.

\section{HER2 Subtype}

The HER2 subtype of breast cancer is classified by amplification of the HER2 oncogene and overexpression of the HER2 transmembrane receptor tyrosine kinase (Ross et al., 2009). HER2 belongs to the epidermal growth factor receptor family, consisting of HER1/EGFR, HER3, and HER4 (Wang, 2017). HER2 is amplified in 15-20\% of all breast cancers, and the HER2 subtype is associated with more aggressive growth and poor prognosis (Waks and Winer, 2019). One of the previous reviews has presented a comprehensive summary of recent advances in HER2-targeted imaging and therapy in nuclear medicine prior to 2018 (Massicano et al., 2018). Herein, we summarize new findings in preclinical studies from 2018 to 2020. We will also discuss imaging studies with other novel targets that evaluate xenograft models within the HER2 subtype. In these recent studies, the BT-474 xenograft model is typically used due to its overexpression of HER2, high tumorigenicity in standard immune compromised mice strains, and high sensitivity to HER2-targeted treatments.

\section{HER2}

Aptamers are single-stranded oligonucleotides that have unique three-dimensional shape to specifically and tightly bind to their protein targets (Ireson and Kelland, 2006). Currently, many therapeutic aptamers are under clinical investigation, including a nucleolin-targeted DNA aptamer for the treatment of renal cell carcinoma (Rosenberg et al., 2014) and several anti-VEGF aptamers for macular degeneration and angioma (EyetechStudy-Group, 2002; Dahr et al., 2007). One recent study demonstrated that a HER2-targeted aptamer can differentiate both HER2-positive breast cancer cells and xenografted mice models from other subtypes of breast cancer through fluorescence imaging (Liu et al., 2018). SH-1194-35, a HER2-targeted DNA aptamer, was labeled with ${ }^{18} \mathrm{~F}$ using click chemistry between the amine-terminal and an $\mathrm{N}$-succinimidyl $4{ }^{18} \mathrm{~F}$-fluorobenzoate $\left({ }^{18} \mathrm{~F}-\mathrm{SFB}\right)$ to form an amide linkage (Aptamer, Figure 2) (Kim et al., 2019). Tumor uptake of this ${ }^{18}$ F-labeled HER2 aptamer in BT474 xenograft models was rather low at $0.62 \pm 0.04 \% \mathrm{ID} / \mathrm{g}$ at $1 \mathrm{~h}$ p. i., but was higher than that in the HER2-negative MDA-
MB-231 xenograft models. The highest uptake was observed in the intestines and kidneys. Although optimization is still needed to increase uptake in the tumor and reduce uptake in normal organs, the translational potential of aptamers to clinical studies opens a new direction for HER2-targeted therapy against breast cancer.

\section{HER3}

HER3 overexpression is a resistance mechanism to several anticancer therapies, including hormone therapy in breast cancer (Johnston et al., 2016). Imaging HER3 may help to explain the mechanism of resistance to standard of care treatments. This approach could also predict the HER3targeted therapeutic efficacy of tyrosine kinase inhibitors neratinib and anti-HER3 antibody patritumab in advanced solid tumors, including breast cancer (Sergina et al., 2007; LoRusso et al., 2013; Mukai et al., 2016; Hyman et al., 2018). Andersson et al. developed a radiolabeled anti-HER3 affibody ${ }^{111}$ In-HEHEHE-Z08698-NOTA (Affibody, Figure 2) which had extremely high binding affinity for HER3 $\left(\mathrm{K}_{\mathrm{D}}\right.$ of $\left.5.4 \pm 0.4 \mathrm{pM}\right)$ (Andersson et al., 2015). The tumor uptake of ${ }^{111}$ In-HEHEHEZ08698-NOTA in the BT-474 xenograft models was $5.1 \pm 0.4$ and $3.7 \pm 0.2$ at 1 and $24 \mathrm{~h}$ p. i., respectively, and T/B ratio increased from $5.3 \pm 0.4$ to $15.5 \pm 0.7$ at these time points. These properties are desirable for clinical translation, given the feasibility of sameday imaging of HER3 expression.

\section{Other Targets in HER2-Positive Models GRPR}

GRPR is also expressed in HER2-positive cells. GRPR belongs to the mammalian bombesin (BBN)-like peptide receptor family (Qu et al., 2018). BBN is a 14-amino acid peptide, originally found in the frog skin (Erspamer et al., 1970; Jensen et al., 2008). One of its mammalian homologs is a gastrin-releasing peptide (GRP) (Qu et al., 2018), which binds specifically to GRPR. RM26 (D-Phe-Gln-Trp-Ala-Val-Gly-His-Sta-Leu-NH2), an antagonist analog of $\mathrm{BBN}$, was conjugated to different lengths of polyethylene glycol $\left(\mathrm{PEG}_{\mathrm{x}}\right)$ and the NOTA chelator for radiolabeling with ${ }^{68} \mathrm{Ga}$ to obtain ${ }^{68} \mathrm{Ga}-\mathrm{NOTA}-\mathrm{PEG}_{\mathrm{x}}-\mathrm{RM} 26$ (Peptides, Figure 2) to optimize the radiotracer's targeting efficiency (Varasteh et al., 2014). ${ }^{68}$ Ga-NOTA-PEG $3-R M 26$, with a three PEG unit linker, was found to have the lowest liver uptake of $0.7 \pm 0.1 \% \mathrm{ID} / \mathrm{g}$ at $2 \mathrm{~h} \mathrm{p}$. i. Tumor uptake in the BT-474 xenograft models was $2.8 \pm 0.4 \% \mathrm{ID} / \mathrm{g}$ with an extremely high $\mathrm{T} / \mathrm{B}$ ratio of $42 \pm 5$ at $2 \mathrm{~h}$ p. i. Therefore, it appears that biological properties can be optimized by insertion of an appropriate length of the PEG spacer between the peptide and radiometal chelator. Since PEG has been widely used for modification of therapeutic peptides and proteins to reduce enzymatic degradation (Roberts et al., 2002), the above study presents a rational approach for optimizing the in vivo pharmacokinetic and binding properties of peptide probes.

\section{VPAC}

TP-3805 is an analog of the pituitary adenylate cyclase-activating peptide (PACAP), which has high affinity for the VPAC [combination of vasoactive intestinal peptide (VIP) and 
PACAP] receptors (Thakur et al., 2013). These receptors are highly expressed in malignant breast cancer. TP-3805 was conjugated to either 1,4,7-triazacyclononane,1-glutaric acid4,7-acetic acid (NODAGA) or 1,4,7,10-tetraazacyclododecane1,4,7,10-tetraacetic acid (DOTA) chelate for radiolabeling with ${ }^{68} \mathrm{Ga}$ to obtain ${ }^{68} \mathrm{Ga}$-NODAGA-peptide or ${ }^{68} \mathrm{Ga}$-DOTA-peptide, respectively (Peptides, Figure 2). PET imaging with these radiotracers was performed to compare their in vivo stability and pharmacokinetic properties in breast cancer xenografts (Kumar et al., 2019). Tumor uptake of ${ }^{68} \mathrm{Ga}-\mathrm{NODAGA}$ peptide in the BT-474 xenograft models was $2.4 \pm 0.3 \% \mathrm{ID} / \mathrm{g}$ at $1 \mathrm{~h}$ p. i., with tumor to muscle (T/M) ratio of $3.4 \pm 0.3$ whereas ${ }^{68}$ Ga-DOTA-peptide showed similar tumor uptake but a lower T/M ratio of $1.9 \pm 0.9$ at $1 \mathrm{~h}$ p. i. Further, ${ }^{68} \mathrm{Ga}$-NODAGA-peptide also showed more flexibility in radiolabeling, higher stability in vitro, and higher cell binding affinity than ${ }^{68}$ Ga-DOTApeptide. These differences may be due to differences in coordination chemistry. For example, $\mathrm{Ga}$ (III) uses all 11 of its coordination sites to form a complex with NODAGA, whereas two sites remain uncoordinated when DOTA is used as a chelator (Viola-Villegas and Doyle, 2009). Although the in vivo stability of both ${ }^{68} \mathrm{Ga}-N O D A G A-$ and ${ }^{68} \mathrm{Ga}$-DOTA-labeled TP-3805 needs improvement, this study suggests that changing the chelator is a strategy to optimize the pharmacologic properties of probes.

\section{Cobalamin}

Vitamin $\mathrm{B}_{12}$, or cobalamin $(\mathrm{Cbl})$, is an essential nutrient required to maintain cell growth and differentiation (Gherasim et al., 2013). Cbl is transported by binding to the transport protein transcobalamin, which is recognized by specific receptors such as CD320 (Quadros and Sequeira, 2013), which is highly expressed in several cancers, including breast cancer (Sysel et al., 2013). Cbl was radiolabeled with ${ }^{89} \mathrm{Zr}\left(\mathrm{t}_{1 / 2}=78.4 \mathrm{~h}\right)$ and used for PET imaging (Kuda-Wedagedara et al., 2017). Tumor uptake of ${ }^{89} \mathrm{Zr}$ Cbl (Figure 1) in HER2-positive MDA-MB-453 xenograft models was $3.8 \pm 0.77 \% \mathrm{ID} / \mathrm{g}$ with $\mathrm{T} / \mathrm{B}$ ratio of about 9.7 at $48 \mathrm{~h}$ p. i. In addition, clearance from blood was evident from 4 to $48 \mathrm{~h}$ with approximately $90 \%$ decrease in activity concentration by $48 \mathrm{~h}$ p. i. A drawback of this radiotracer is its high uptake in the kidney. This study demonstrates the feasibility of labeling vitamin $\mathrm{B} 12$ as a tracer and use it for breast cancer imaging.

In summary, HER2 remains an important target for theranostic development. Several other promising targets in the HER2 subtype of breast cancer such as HER3, GRPR, and vitamin B12 offer additional options for targeted therapy, with their respective companion diagnostic imaging agents readily available for assessing target engagement or monitoring response to treatment. Further investigations are still needed for optimization and validation of these nuclear imaging agents.

\section{Triple-Negative Breast Cancer}

Triple-negative breast cancer (TNBC) is characterized by the absence of ER and PR expression, or lack of HER2 overexpression (Waks and Winer, 2019). TNBC makes up approximately $15 \%$ of all breast cancers (Waks and Winer, 2019). The absence of these receptors has long limited the treatment of patients with TNBC to chemotherapy, with its accompanying serious adverse effects and drug resistance. Hence, patients with TNBC are faced with a grim prospect of poor prognosis, high rate of distant metastasis and short survival time (Bianchini et al., 2016; He et al., 2018). However, a new era in TNBC treatment has recently begun with the FDA-approval of drugs targeting PD-L1 (e.g., atezolizumab), and trophoblast antigen 2 (Trop-2) (e.g., sacituzumab govitecan) (Bardia et al., 2019; Cyprian et al., 2019). Development of new PET and SPECT imaging agents that inform on the status of new therapeutic targets could help guide treatment options for patients with TNBC. In the preclinical studies of new imaging probes described below, MDA-MB-231 and MDA-MB-468 xenograft models are typically used as animal models for TNBC.

\section{EGFR}

TNBC patients with higher expression of the epidermal growth factor receptor (EGFR) have shorter overall survival (Vallböhmer et al., 2005, Zhang et al., 2003). Panitumumab combined with chemotherapy showed promising results in a phase II clinical trial (Cowherd et al., 2015). Thus, imaging EGFR with a radiolabeled panitumumab Fab (PmFab) could afford a tool to monitor response to this combination treatment. The SPECT imaging agent ${ }^{99} \mathrm{~m}_{\mathrm{Tc}}-\mathrm{PmFab}-\mathrm{His}_{6}$ (Fab, Figure 2) was prepared by conjugating PmFab and the hexahistidine peptide $\left(\mathrm{His}_{6}\right)$ which serves as a chelate for ${ }^{99 \mathrm{~m}} \mathrm{Tc}$ labeling (Ku et al., 2019a). Tumor uptake in MDA-MB-468 xenograft models was $15 \pm 3.1 \% \mathrm{ID} / \mathrm{g}$ with $\mathrm{T} / \mathrm{B}$ ratio of $12 \pm 1.4$ at $24 \mathrm{~h} \mathrm{p}$. i., indicating that ${ }^{99 \mathrm{~m}} \mathrm{Tc}$ PmFab-His ${ }_{6}$ is a promising probe for imaging EGFR and may be used to monitor the response to EGFR-directed therapies.

\section{Chemokine-like Receptor 1}

Chemerin is known to be involved in angiogenesis, cancer-related inflammation, and insulin resistance (Perumalsamy et al., 2017). The chemokine-like receptor 1 (CMKLR1) is a chemotactic cellular receptor for chemerin (Pachynski et al., 2019). CMKLR1 and chemerin have recently been recognized as modulators of tumor proliferation (Shin and Pachynski, 2018). Increasing chemerin expression in the breast tumor microenvironment can suppress tumor growth (Pachynski et al., 2019). Further, high mRNA expression of CMKLR1 is associated with a longer relapse-free survival of breast cancer patients (Treeck et al., 2019). The first imaging of CMKLR1 in vivo was performed with a family of five novel CMKLR1 peptides derived from chemerin- 9 and labeled with ${ }^{68} \mathrm{Ga}$ (Erdmann et al., 2019) (Peptides, Figure 2). One of the radiotracers, ${ }^{68} \mathrm{Ga}$-DOTAADX-CG34, showed the highest tumor uptake with $6.2 \pm 0.5 \%$ ID/ $\mathrm{g}$ in CMKLR1-positive DU4475 (TNBC) xenograft models, while ${ }^{68} \mathrm{Ga}$-DOTA-AHX-CG34 presented the highest T/B ratio of $5.9 \pm$ 0.7 at 1 h p. i., and ${ }^{68}$ Ga-DOTA-KCap-CG34 the lowest kidney and liver uptake. Since high CMKLR1 expression is associated with longer relapse-free survival, CMKLR1-targeted probes are promising prognostic tools for breast cancer.

\section{Histone Deacetylases}

Histone deacetylases (HDACs) are a class of enzymes that modulate transcription and therefore alter gene expression (Bolden et al., 2006; Falkenberg and Johnstone, 2014). Four HDAC inhibitors (HDACi), 
namely romidepsin, panobinostat, vorinostat, and belinostat, have been approved by the Food and Drug Administration (FDA) for the treatment of T-cell lymphoma and multiple myelomas, while several other HDACi compounds are under clinical investigation (Singh et al., 2018). Therefore, imaging HDAC is needed for non-invasive assessment of its expression in the body and prediction of response to HDAC-targeted treatment. Preclinical studies have shown that HDACi is toxic to TNBC cells and decreases tumorigenesis in vivo (Tate et al., 2012). CUDC-101, a small molecule HDACi, is currently in phase I clinical trials for the treatment of advanced breast cancer (Shimizu et al., 2014). CUDC-101 was labeled with ${ }^{64} \mathrm{Cu}$ to obtain ${ }^{64} \mathrm{Cu}-\mathrm{HDACi}$ (Figure 1) for PET imaging of TNBC xenografts (Meng et al., 2013). Tumor uptake of ${ }^{64} \mathrm{Cu}-\mathrm{HDACi}$ in was $2.2 \pm$ $0.18 \% \mathrm{ID} / \mathrm{g}$, as well as high T/B ratio of $4.4 \pm 0.88$ at $24 \mathrm{~h}$ p. i. with moderate uptake in the liver and kidney $(3.2 \pm 1.3$ and $1.9 \pm$ $0.06 \% \mathrm{ID} / \mathrm{g}$, respectively). Thus, ${ }^{64} \mathrm{Cu}-\mathrm{HDACi}$ shows promise for clinical translation to monitor the response to HDACi treatment in breast cancer.

\section{C-Myc Proto-Oncogene}

The c-myc proto-oncogene (MYC) is known to play important roles in mRNA regulation, cell proliferation, cell metabolism, and cell death (Horiuchi et al., 2012; Stine et al., 2015). MYC expression is found in $87 \%$ of TNBC patients (164 of 187) and associated with poor survival (Bouchalova et al., 2015). There is also evidence that MYC overexpression contributes to drug resistance in patients with TNBC (Carey et al., 2018, Lee et al., 2017). However, directly targeting of the MYC gene remains a challenge, and alternate approaches have been developed (Horiuchi et al., 2014). It has been shown that upregulation of MYC leads to increased surface expression of transferrin receptor (TfR) (O'Donnell et al., 2006), hence ${ }^{89} \mathrm{Zr}$ transferrin was developed as a potential probe for MYC status and tumor burden in several cancer models, such as prostate cancer and lymphoma (Holland et al., 2012; Doran et al., 2016). Recently, PET imaging with ${ }^{89} \mathrm{Zr}$-transferrin in TNBC models has also been performed using MDA-MB-231 and MDA-MB157 xenografts, showing similar accumulation of the radiotracer in both models with $4 \% \mathrm{ID} / \mathrm{g}$ at $48 \mathrm{~h}$ p. i. (Henry et al., 2018). In patient-derived xenograft models of TNBC PET imaging with ${ }^{89} \mathrm{Zr}$-transferrin at $48 \mathrm{~h}$ p. i. delineated xenografted tumors from normal organs, indicating the potential of ${ }^{89} \mathrm{Zr}$-transferrin as a probe for MYC to monitor response to treatments that modulate this oncogene.

\section{Tissue Factor}

Tissue factor (TF), also known as thrombokinase or CD142, has been confirmed to be overexpressed on TNBC cells (Callander et al., 1992). Importantly, a high level of TF also contributes to progression and poor survival in TNBC patients (Ruf et al., 2010; Ueno et al., 2000). ALT-836, a chimeric anti-human TF monoclonal antibody ( $\mathrm{mAb}$ ), has been used for the treatment of solid tumors that overexpress TF in a clinical trial (Clinical Trials.gov Identifier: NCT01325558). A radiolabeled antibody fragment, ${ }^{64} \mathrm{Cu}-\mathrm{NOTA}-\mathrm{ALT}-836-\mathrm{Fab}$ (Fab, Figure 2), was developed and shown to have an uptake level of about $4 \%$ ID/ $\mathrm{g}$ with $\mathrm{T} / \mathrm{B}$ ratio of 2 at $24 \mathrm{~h}$ p. i. in MDA-MB-231 xenograft models (Shi et al., 2015). Therefore, targeting TF could be a potential way for imaging and therapy of TNBC.

\section{CXCR4}

Similar to its involvement in the luminal subtype, CXCR4 is also a potential target for theranostics of TNBC using RNA interference (RNAi) technology, a powerful tool in gene therapy research (Bottai et al., 2017). The delivery of small-interference RNA (siRNA) can affect the efficacy of RNAi therapy in vivo (Chen et al., 2018). A ${ }^{99 m}$ Tc-labeled siRNA was used to target CXCR4 in breast cancer xenografts for tracing the delivery of siRNAs in vivo (Fu et al., 2016). Due to its fast blood clearance, the tumor uptake of ${ }^{99 \mathrm{~m}}$ Tc-HYNIC-siRNA1 (siRNA, Figure 2) in MDA-MB-231 xenograft models increased from $4.5 \pm 0.47$ to $8.4 \pm 1.1 \% \mathrm{ID} / \mathrm{g}$ at 1 and $6 \mathrm{~h}$ p. i., respectively, with corresponding increase in $\mathrm{T} / \mathrm{B}$ ratio from 0.6 to 4.8 . In comparison, tumor uptake of the siRNA control was lower, indicating specific targeting of ${ }^{99 \mathrm{~m}}$ Tc-HYNICsiRNA1 to breast cancer. This probe may be a useful tool to predict the efficacy of RNAi gene therapy.

\section{Mucin 1}

Mucin 1 (MUC1) is a cell surface glycoprotein and expressed in over $90 \%$ of all breast cancers (Miller-Kleinhenz et al., 2015) and $94 \%$ of the TNBC subtype (Siroy et al., 2013). High expression of MUC1 has also been found to be associated with metastases and poor survival (Kim et al., 2020, McGuckin et al., 1995), and MUC1 has been reported to contribute to immune escape in TNBC, indicating that MUC1 is a potential immunotherapeutic target for TNBC (Maeda et al., 2018). Several clinical trials targeting MUC1 are ongoing in breast cancer patients (Apostolopoulos et al., 2006; Ibrahim et al., 2011, Tang et al., 2017). Therefore, MUC1 is recognized as a promising marker for theranostics of breast cancer and has been targeted for imaging agent development. One example is ${ }^{99 \mathrm{~m}} \mathrm{Tc}$-labeled mesoporous silica nanoparticles (MSNs), ${ }^{99 \mathrm{~m}} \mathrm{Tc}-\mathrm{S} 1$-apMUC1 (Nanoparticles, Figure 2), with the MSN functionalized with positively charged aminopropyl groups and gated with negatively charged MUC1 aptamer via electrostatic and hydrogen bonding interactions (Pascual et al., 2017). Tumor uptake of ${ }^{99 \mathrm{~m}} \mathrm{Tc}-\mathrm{S} 1$-apMUC1 was up to $20 \% \mathrm{ID} / \mathrm{g}$ with $\mathrm{T} / \mathrm{B}$ ratio of about 7 at $2 \mathrm{~h}$ p. i. Notably, ${ }^{99} \mathrm{~m}$ Tc-S1-apMUC1 uptake in the liver and spleen was as low as about $1 \% \mathrm{ID} / \mathrm{g}$, suggesting that ${ }^{99 \mathrm{~m}} \mathrm{Tc}-\mathrm{S} 1-$ apMUC1 nanoparticles bypassed elimination by the mononuclear phagocytic system (MPS). Its uptake in the lung was $15 \% \mathrm{ID} / \mathrm{g}$, possibly due to the high-expression of MUC1 in this organ. High kidney uptake of about $20 \% \mathrm{ID} / \mathrm{g}$ provides evidence of renal clearance. ${ }^{99 \mathrm{~m}} \mathrm{Tc}-\mathrm{S} 1$-apMUC1 SPECT imaging can be a useful tool to detect MUC1 expression and predict the prognosis of MUC1-targeted treatment.

\section{DUAL-RECEPTOR TARGETED IMAGING OF BREAST CANCER}

Recently, multiple antibodies, peptides, and nanoparticles have been developed to target two receptors simultaneously on the same cell or to elicit contact between two different cell types 
(Ehlerding et al., 2018). Those dual-receptor targeting strategies have multiple advantages over the mono-targeted ones such as improved target specificity and biodistribution in vivo (Kontermann, 2012). Most importantly, bispecific constructs targeting receptors expressed on the same cancer cell have the potential to overcome resistance mechanisms associated with mono-targeted therapies. Certain bispecific constructs have been designed so that they bind two distinct cells such as $\mathrm{T}$ cells and cancer cells and can therefore re-direct immune cells to tumor cells to stimulate cytotoxic activity (Ehlerding et al., 2018; Labrijn et al., 2019). The concept of dual-receptor targeting is of particular interest in heterogeneous subtypes of breast cancer, where a mono-targeted approach might fail to treat lesions absent of its target, especially in metastatic disease (McGuire et al., 2015; Peart, 2017). In this section, we discuss the progress made in the preclinical development and evaluation of bispecific agents with regards to imaging of breast cancer, independent of its molecular subtypes.

\section{GRPR/FA}

Folate (FA) is a basic component of cell metabolism and DNA synthesis and repair. Folate receptor (FR) is a membrane-bound protein that binds and transports FA into cells (Frigerio et al., 2019) and its overexpression has been confirmed in all clinical breast cancer subtypes (Karuppaiah et al., 2020; Wang et al., 2020; Zhang et al., 2014b). As described above, overexpression of GRPR is also observed in $96 \%$ of all breast cancer tissues (Dalm et al., 2015). Therefore, an heterobivalent agent targeting GRPR and FR could improve breast cancer imaging. The radioconjugate ${ }^{99 \mathrm{~m}}$ Tc-BBN-FA (Peptides, Figure 2) has been synthesized to target the GRPR with the BBN portion and the FR with the FA portion for SPECT imaging in preclinical models of breast cancer (Aranda-Lara et al., 2016b). Tumor uptake of ${ }^{99} \mathrm{~m}$ Tc-BBN-FA in T47D xenograft models was $5.4 \pm 0.97 \%$ $\mathrm{ID} / \mathrm{g}$ at $2 \mathrm{~h} \mathrm{p}$. i. and remained stable at $24 \mathrm{~h} \mathrm{p}$. i. with values of $2.5 \pm 0.63 \% \mathrm{ID} / \mathrm{g}$. Further, very fast blood clearance contributed to high T/B ratio of 124 at $24 \mathrm{~h}$ p. i. High uptake in the pancreas was observed due to the high GRPR expression in this organ. Tumor uptake of ${ }^{99 \mathrm{~m}} \mathrm{Tc}-\mathrm{BBN}-\mathrm{FA}$ was higher than that of ${ }^{99 \mathrm{~m}} \mathrm{Tc}-\mathrm{BBN}$ or ${ }^{99 \mathrm{~m}} \mathrm{Tc}-\mathrm{FA}$ alone, demonstrating the advantage of the bispecific construct. BBN and FA were also labeled with ${ }^{177} \mathrm{Lu}\left(\mathrm{t}_{1 / 2}=6.71\right.$ days) for SPECT imaging in T47D xenograft models (Aranda-Lara et al., 2016a). ${ }^{177} \mathrm{Lu}-\mathrm{BBN}-\mathrm{FA}$ (Peptides, Figure 2) showed similar excellent tumor uptake and biodistribution compared with the ${ }^{99 \mathrm{~m}} \mathrm{Tc}$-labeled variant. In addition, when administering $74 \mathrm{MBq}$ of each radiotracer, ${ }^{177} \mathrm{Lu}-\mathrm{BBN}-\mathrm{FA}$ was shown to substantially enhance radiation absorbed dose in the tumor with up to $24 \pm 2.1 \mathrm{~Gy}$, as compared with those of the mono-targeted ${ }^{177} \mathrm{Lu}-\mathrm{BBN}$ and ${ }^{177} \mathrm{Lu}-\mathrm{FA}$, which were lower by 47 and $67 \%$, respectively. Clearly, the bispecific construct is also advantageous for therapy, as it can deliver greater radiation dose to the tumor. Taken together, these studies demonstrate that GRPR/FA dualreceptor targeted imaging perform better than its respective mono-specific variants and has potential for clinical translation for imaging and targeted radiotherapy of breast cancer.

\section{GRPR/NPY $\left(\mathbf{Y}_{1}\right) R$}

A study conducted on human breast cancer patient tissues reported that $51 \%$ of them $(32 / 63)$ showed an overexpression of GRPR together with another receptor called the neuropeptide $\mathrm{Y}$ receptor subtype $1\left(\mathrm{NPY}\left(\mathrm{Y}_{1}\right) \mathrm{R}\right)$ (Reubi et al., 2002). Thus, a series of ${ }^{68} \mathrm{Ga}$ labeled heterobivalent peptidic ligands were synthesized to target both receptors with the goal of achieving increased binding to breast cancer cells over the mono-specific targeting agents (Vall-Sagarra et al., 2018). The best bispecific agent in this study was found to be the compound, ${ }^{68} \mathrm{Ga}-24$ (Peptides, Figure 2), with tumor uptake of $3.1 \pm$ $0.33 \% \mathrm{ID} / \mathrm{g}$ and $\mathrm{T} / \mathrm{B}$ ratio of $2.7 \pm 0.43$ at $130 \mathrm{~min} \mathrm{p.} \mathrm{i.} \mathrm{in} \mathrm{the} \mathrm{T47D}$ xenograft models. Conversely, tumor uptake of the GRPR or $\mathrm{NPY}\left(\mathrm{Y}_{1}\right) \mathrm{R}$ mono-specific targeted agents were lower, confirming the improved tumor uptake of the bispecific construct over the mono-targeted agents.

\section{$\alpha_{v} \beta_{3} / C D 13$}

The integrin $\alpha_{v} \beta_{3}$ receptor and CD13 are two other receptors whose expression levels are correlated with neoangiogenesis, invasiveness, metastasis, and poor overall survival in breast cancer (Ranogajec et al., 2012; Rolli et al., 2003). The ligands RGD and NGR bind to $\alpha_{v} \beta_{3}$ and $\mathrm{CD} 13$, respectively, and have been used as anti-angiogenic drugs in radionuclide therapy (Debordeaux et al., 2018; Goodman and Picard, 2012). Hence, a bispecific agent derived from these mono-specific targeting agents, ${ }^{68}$ Ga-NGR-RGD (Peptides, Figure 2), has recently been synthesized for PET imaging in breast cancer xenografts (Gai et al., 2020). Tumor uptake in the MCF-7 xenograft models was $1.0 \pm$ $0.16 \% \mathrm{ID} / \mathrm{g}$ with T/B ratio of about 6 . Further, tumor uptake of ${ }^{68} \mathrm{Ga}$ NGR-RGD was significantly higher than that of ${ }^{68} \mathrm{Ga}-\mathrm{NGR}$ and ${ }^{68} \mathrm{Ga}$ RGD at $1 \mathrm{~h}$ p. i. More importantly, ${ }^{68} \mathrm{Ga}-\mathrm{NGR}$-RGD detected lung metastases in MCF-7 xenografts. This study represents another proof of concept for the increased tumor targeting ability of bispecific agents over the mono-specific constructs.

\section{EGFR/HER2}

As previously discussed, HER2 represents a common therapeutic target in the HER2 subtype of breast cancer. However, HER2directed therapies such as trastuzumab can develop resistance through several mechanisms including heterodimerization of EGFR with HER2 (Dua et al., 2010). A ${ }^{64} \mathrm{Cu}$-labeled bispecific antibody fragment, ${ }^{64} \mathrm{Cu}-\mathrm{NOTA}-\mathrm{Fab}-\mathrm{PEG}_{24}$-EGF (Fab, Figure 2), was thus developed to inhibit the EGFR and HER2 receptors simultaneously (Kwon et al., 2017). In order to increase the blood circulation time and potentially increase tumor uptake of the tracer, Kwon et al. linked the Fab of the trastuzumab to that of the EGF through a $\mathrm{PEG}_{24}$ linker, conjugated the resulting construct to NOTA, and radiolabeled with ${ }^{64} \mathrm{Cu}$ to obtain ${ }^{64} \mathrm{Cu}-\mathrm{NOTA}-\mathrm{Fab}-\mathrm{PEG}_{24}$-EGF. In the MDA-MB-231/H2N xenograft model, which is characterized by low expression of HER2 and moderate expression of EGFR, the bispecific ${ }^{64} \mathrm{Cu}-\mathrm{NOTA}-\mathrm{Fab}-\mathrm{PEG}_{24}$-EGF showed much greater tumor uptake $(4.9 \% \mathrm{ID} / \mathrm{g}$ at $48 \mathrm{~h} \mathrm{p}$. i.) than those of the radiolabeled Fab (against HER2) and EGF monomers (1.9\% ID/g and $0.7 \% \mathrm{ID} / \mathrm{g}$, respectively). The highest uptake of ${ }^{64} \mathrm{Cu}-\mathrm{NOTA}-\mathrm{Fab}-\mathrm{PEG}_{24}$-EGF in normal organs was observed in the kidney with $25 \pm 4.2 \% \mathrm{ID} / \mathrm{g}$. Further investigation is needed to evaluate the ability of PET imaging with ${ }^{64} \mathrm{Cu}-\mathrm{NOTA}-\mathrm{Fab}-\mathrm{PEG}_{24}$-EGF to predict treatment response (efficacy) in HER2-and EGFR-directed therapies. 


\section{T-Cell/CEA}

Another bispecific agent is the AMG211, a T-cell engager antibody construct used in phase I trials for targeting carcinoembryonic antigen (CEA) (Kebenko et al., 2018; Pishvaian et al., 2016), an established therapeutic target in a number of solid tumors, including breast cancer (Tang et al., 2016, Wang et al., 2017). A PET companion diagnostic agent for AMG211 was recently developed by radiolabeling the antibody with ${ }^{89} \mathrm{Zr}$ to obtain ${ }^{89} \mathrm{Zr}$-AMG211 (Antibodies, Figure 2) (Waaijer et al., 2018). Tumor uptake of ${ }^{89} \mathrm{Zr}$-AMG211 in CEA-positive BT-474 xenograft models was $3.8 \pm 1.1 \% \mathrm{ID} / \mathrm{g}$ with $\mathrm{T} / \mathrm{B}$ ratio of about 10 at $24 \mathrm{~h}$ p. i., while uptake was significantly lower in the CEA-negative HL-60 xenograft models $(p<0.01)$. A major drawback of this imaging agent is its extremely high uptake in the kidneys ( 150\% ID/g).

\section{EGFR/C-MET}

Amivantamab is a new bispecific antibody with multiple mechanisms of action, including inhibition of the EGFR and the hepatocyte growth factor receptor (HGFR/c-MET) pathways (Moores et al., 2016). In a recent report it was radiolabeled with ${ }^{89} \mathrm{Zr}$ via a desferrioxamine chelate (DFO) to create a companion diagnostic imaging agent for this bispecific antibody (Cavaliere et al., 2020) (Bispecific antibodies, Figure 2). As overexpression of EGFR and c-MET was found in TNBC and associated with progression of the disease, the resulting $\left[{ }^{89} \mathrm{Zr}\right] \mathrm{ZrDFO}$-amivantamab radioconjugate was evaluated in TNBC xenograft models (Cavaliere et al., 2020; Chae et al., 2016). Three xenografts were used, MDA-MB-468, MDA-MB-231, and MDA-MB-453, which are characterized by high, moderate, and negative co-expression of EGFR and c-MET, respectively (Figure 5). PET/CT imaging with $\left[{ }^{89} \mathrm{Zr}\right] \mathrm{ZrDFO}-$ amivantamab showed its ability to detect graded levels of EGFR and c-MET with standard uptake values $\left(\mathrm{SUV}_{\text {mean }}\right)$ of $6.0 \pm 1.1,4.2 \pm$ $1.4,1.5 \pm 1.496$ h p. i. in MDA-MB-468, MDA-MB-231, and MDAMB-453, respectively (Figure 5) (Cavaliere et al., 2020). Further, tumor uptake of $\left[{ }^{89} \mathrm{Zr}\right] \mathrm{ZrDFO}$-amivantamab was significantly higher than those of the radiolabeled single-arm parent antibodies $\left[{ }^{89} \mathrm{Zr}\right.$ ] ZrDFO- $\alpha$-EGFR or [ ${ }^{89} \mathrm{Zr}$ ]ZrDFO- $\alpha$-c-MET. This imaging agent has the potential to be clinically translated to provide a more quantitative assessment of the total expression of EGFR and c-MET for patient selection in clinical trials that evaluate the efficacy of amivantamab.

As more bispecific agents are being developed to overcome resistance and limitations associated with mono-targeted therapies, there is an increasing need for development of their companion diagnostic imaging agents. Molecular imaging has the potential to accelerate the development of novel bispecific constructs by predicting response and selecting patients most likely to benefit from these dual-targeted therapies.

\section{PRECLINICAL TARGETED THERAPY AGENTS FOR BREAST CANCER}

The two strategies to incorporate cytotoxic payloads into targeting agents are to conjugate non-specific cytotoxic drugs, and to attach radioisotopes that emit DNA-damaging energy. These targeting agents typically employ peptides and antibodies,

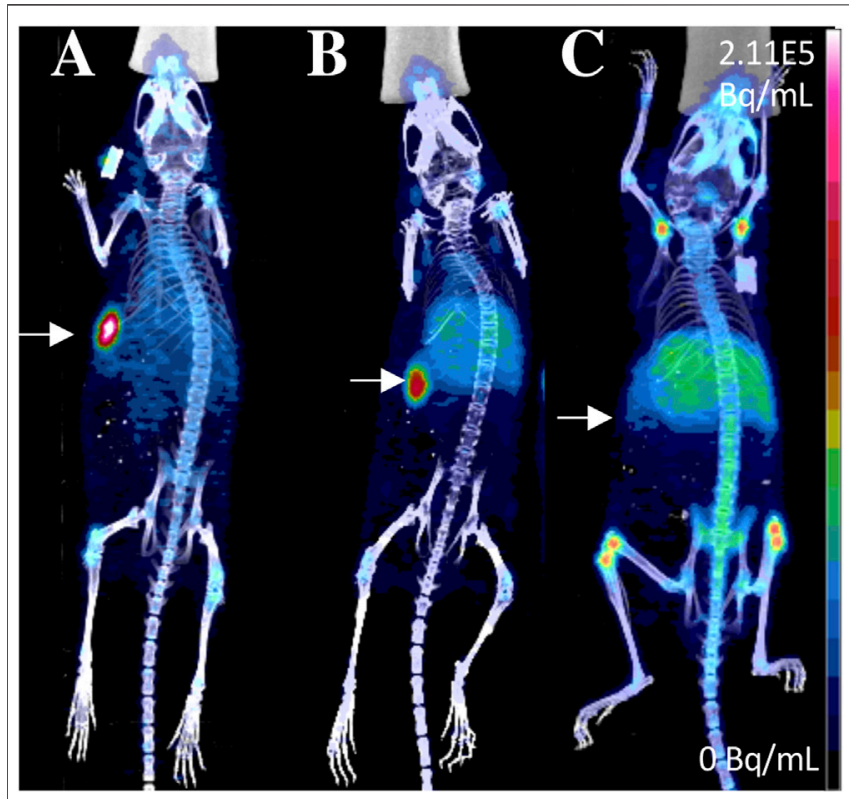

FIGURE 5 | PET/CT imaging of [ ${ }^{89} \mathrm{Zr}$ ]ZrDFO-Amivantamab in MDA-MB468 (A), MDA-MB-231 (B) and MDA-MB-453 (C) xenografts of TNBC at $96 \mathrm{~h}$ p. i. Tumors are marked with arrows (Cavaliere et al., 2020). The general structure of $\left[{ }^{89} \mathrm{Zr}\right] \mathrm{ZrDFO}-A m i v a n t a m a b$ was shown in Figure $\mathbf{2 H}$

as they can be chemically modified with the cytotoxic payloads while maintaining their pharmacokinetic properties and specific binding to target proteins on the surface of cancer cells. These vehicles may internalize in the cancer cell once bound to the target protein and deliver their cytotoxic payload.

\section{Targeted Radionuclide Therapy}

Targeted radionuclide therapy (TRT) combines the specificity of targeting molecules and the cytotoxicity of ionizing radiation as an approach to overcome resistance to other drugs (Gill et al., 2017). The diverse combinations of targeting molecules and radioisotopes provide flexible choices in the treatment of the different molecular subtypes of breast cancer for both primary and metastatic disease.

There are three types of radiation related to TRT: $\beta$-particles, $\alpha$ particles, and Auger electrons, which can irradiate volumes with multicellular, cellular, and subcellular dimensions, respectively (Gill et al., 2017). The $\beta$-emitters are considered ideal for targeting large tumors due to their long range path length of 0.05-12.0 $\mathrm{mm}$ in tissue, and the ability to induce formation of radical species that are damaging to DNA (Pouget et al., 2011). The a emitters, with a short-range path length of $20-100 \mu \mathrm{m}$, has a high linear energy transfer and are ideal for treating micrometastases and blood or bone marrow malignancies (Dahle et al., 2007). Finally, Auger electrons have the shortest range of $1-23 \mu \mathrm{m}$ and are suitable for targeting single cells (Ku et al., 2019b).

Recently, ${ }^{177} \mathrm{Lu}$ and ${ }^{111}$ In have attracted the most attention for TRT of breast cancer. ${ }^{177} \mathrm{Lu}$ is a low-energy $\beta$-emitter $\left(0.497 \mathrm{MeV}_{\max }\right)$ with tissue penetration of up to $1.6 \mathrm{~mm}$, which considerably lowers the dosimetry (i.e., radiation dose to organs and whole body) for patients (Massicano et al., 
TABLE 2 | Preclinical targeted therapy agents for the different subtypes of breast cancer. Those with additional imaging properties are checked in the theranostics column.

\begin{tabular}{|c|c|c|c|c|c|}
\hline Target & Agent & Structure & $\begin{array}{l}\text { Imaging } \\
\text { and } \\
\text { therapy }\end{array}$ & Models & References \\
\hline \multicolumn{6}{|c|}{ HER2-positive } \\
\hline \multirow[t]{3}{*}{ HER2 } & ${ }^{89} \mathrm{Zr}-\mathrm{AF}-\mathrm{Lx}$-trastuzumab & Antibody conjugate & $\sqrt{ }$ & JIMT-1 & Sijbrandi et al. (2017) \\
\hline & ${ }^{111}$ In-NLS-trastuzumab & Antibody-peptide conjugate & - & MDA-MB-361 & Costantini et al. (2010) \\
\hline & $\begin{array}{l}{ }^{111} \text { In-trastuzumab-DOX-APTES- } \\
\text { PEG-SPIONs }\end{array}$ & $\begin{array}{l}\text { Nanoparticles, antibody and } \\
\text { chemotherapeutics }\end{array}$ & $\sqrt{ }$ & SK-BR-3 & Zolata et al. (2015) \\
\hline HER2 & ${ }^{177}$ Lu-AuNPs-trastuzumab- & Nanoparticle-antibody conjugate & - & MDA-MB-231-H2N; MDA-MB- & Yook et al. (2020) \\
\hline $\begin{array}{l}\text { and } \\
\qquad \text { EGFR }\end{array}$ & panitumumab & & & 468; BT-474 & \\
\hline \multicolumn{6}{|c|}{ Triple negative } \\
\hline EGFR & ${ }^{111}$ In-bn-DTPA-nimotuzumab & Antibody & - & MDA-MB-468 & Chan et al. (2020) \\
\hline PSMA & ${ }^{177}$ Lu-PSMA-617/68 Ga-PSMA-11 & Small molecule & $\sqrt{ }$ & MDA-MB-231 & Morgenroth et al. (2019) \\
\hline \multicolumn{6}{|c|}{ Subtype independent } \\
\hline \multirow[t]{2}{*}{ GRPR } & ${ }^{177}$ Lu-DOTA-DN(PTX)-BN & $\begin{array}{l}\text { Nanoparticle-peptide conjugate } \\
\text { loaded with chemotherapeutics }\end{array}$ & $\sqrt{ }$ & T47D & $\begin{array}{l}\text { Gibbens-Bandala et al. } \\
\text { (2019a) }\end{array}$ \\
\hline & ${ }^{177}$ Lu-BN-PLGA(PTX) & $\begin{array}{l}\text { Nanoparticle-peptide conjugate } \\
\text { loaded with chemotherapeutics }\end{array}$ & $\sqrt{ }$ & MDA-MB-231 & $\begin{array}{l}\text { Gibbens-Bandala et al. } \\
\text { (2019b) }\end{array}$ \\
\hline FA & ${ }^{99}$ TC-PEG-PAMAM G4-FA-5FU & $\begin{array}{l}\text { Nanoparticle-peptide conjugate } \\
\text { loaded with chemotherapeutics }\end{array}$ & $\sqrt{ }$ & MCF-7 & Narmani et al. (2017) \\
\hline Nucleolin & ${ }^{111}$ In-BnDTPA-F3 & Peptide & $\sqrt{ }$ & MDA-MB-231-H2N & Cornelissen et al. (2012) \\
\hline
\end{tabular}

2018). The long half-life of ${ }^{177} \mathrm{Lu}$ (6.71 days) also provides advantages in production and transportation to facilities that do not have the capability to produce this radioisotope. In contrast, ${ }^{111}$ In is an Auger electron with low-energy $(<30 \mathrm{keV})$ and a very short path length of less than $10 \mu \mathrm{m}$, and must be delivered to the tumor cell nucleus to achieve maximum cellkilling ability via DNA double-strand breaks (Valkema et al., 2002; Boswell and Brechbiel, 2005). The radiopharmaceuticals based on Auger electrons can be enhanced by increasing nuclear localization, either by attaching a peptide with an nuclear localization sequence (NLS) (Costantini et al., 2010), or coadminister with other pharmaceuticals capable of intensifying nuclear localization (Bailey et al., 2007). In this section, we review examples of new antibody drug conjugates and TRT in breast cancer, as listed in Table 2.

\section{HER2-Positive Breast Cancer}

Many kinds of HER2-directed agents have been labeled with different radionuclides and previously reviewed (Massicano et al., 2018). Here, we summarize recent strategies on the preclinical development of HER2-targeted therapy agents not discussed by Massicano et al.

Sijbrandi et al. used a novel strategy of conjugating an ethylenediamine platinum $(L x)$ to trastuzumab (Sijbrandi et al., 2017), with the expected effects of improved aqueous solubility for the $L x$-payload complexes and the $L x$ able to coordinate to unique amino acids, including methionines, cysteines, and histidines, which is a valuable alternative to the currently used strategy of coupling to lysines and cysteines (Messori et al., 2014). In this study, auristatin F (AF) coordinated $L x$ was conjugated to trastuzumab and radiolabeled with ${ }^{89} \mathrm{Zr}$ to obtain the companion diagnostic agent, ${ }^{89} \mathrm{Zr}$-AF- $L x$-trastuzumab. The therapeutic efficacy of AF- $L x$-trastuzumab was evaluated in HER2-positive and trastuzumab resistant JIMT-1 xenograft models. All tumors regressed completely with no regrowth observed until the end of the experiment at day 125, indicating that all xenografted tumors had complete response in mice treated with AF- $L x$ trastuzumab. In contrast, only $25 \%$ of mice had complete response when treated with the ado-trastuzumab emtansine (T-DM1) control. The therapeutic efficacy of AF-Lxtrastuzumab demonstrates its superiority over the T-DM1 standard-of-care. While these results are promising, toxicity studies in higher species are needed before translation to clinical evaluation.

An ${ }^{111}$ In-labeled trastuzumab was modified with the nuclear localization sequence (NLS) peptides (CGYGPKKKRKVGG) to obtain ${ }^{111}$ In-NLS-trastuzumab (Costantini et al., 2010). Tumor growth was delayed in the HER2-positive MDA-MB-361 xenografts treated with a single dose of ${ }^{111}$ In-NLS-trastuzumab $(9.25 \mathrm{MBq}, 4 \mathrm{mg} / \mathrm{kg})$. On the contrary, ${ }^{111} \mathrm{In}$-NLS-trastuzumab had no effect on tumor growth of the HER2-negative MDA-MB231 xenografts. When two doses $(9.25 \mathrm{MBq}, 4 \mathrm{mg} / \mathrm{kg})$ of ${ }^{111} \mathrm{In}$ NLS-trastuzumab were administered two weeks apart, the survival time of MDA-MB-361 xenograft models was significantly prolonged and $50 \%$ of the tumors (3 of 6 mice) regressed completely. Based on these results, ${ }^{111}$ In-NLStrastuzumab achieved high targeted radiotherapeutic efficacy in HER2-positive tumors.

Nanotechnology represents a hot area in drug delivery research. Superparamagnetic iron oxide nanoparticles (SPIONs) with appropriate surface modification have been 
widely used for biomedical applications. For example, SPIONs decorated with trastuzumab-doxorubicin (DOX) conjugate and labeled with ${ }^{111}$ In were evaluated as a theranostic agent in HER2positive SK-BR-3 xenograft models (Zolata et al., 2015). Tumor uptake of the ${ }^{111}$ In-labeled SPIONs was $13 \pm 0.76 \% \mathrm{ID} / \mathrm{g}$ with T/B ratio of 10 at $48 \mathrm{~h}$ p. i. After treatment with ${ }^{111}$ In-labeled trastuzumab-DOX conjugated SPIONs, tumor volumes were reduced by $36 \%$ in 3 weeks, while the tumor volumes of the control group were 4-fold larger than those in the treated group. Therapeutic efficacy was increased due to appropriate surface modification on SPIONs to prolong circulation time, specific targeting by trastuzumab, controlled DOX release, and Auger electrons and gamma rays of the ${ }^{111}$ In radionuclide.

Recent studies reported that trastuzumab resistance in HER2positive cells might be due to activation of the EGFR pathway and hence increased EGFR protein expression. The heterodimers formed between EGFR and HER2 may circumvent the antitumor effects of HER2-targeted therapies. A bispecific agent ${ }^{177} \mathrm{Lu}$-AuNPs-trastuzumab-panitumumab was developed to overcome resistance to trastuzumab by targeting both HER2 and EGFR simultaneously (Yook et al., 2020). This dualreceptor-targeted agent was specifically bound and internalized by breast cancer cells that expressed HER2, or EGFR, or both, and showed high absorbed radiation doses with 36-119 Gy in the cell nucleus treated with ${ }^{177} \mathrm{Lu}$-AuNPs-trastuzumab-panitumumab. Although the study was conducted in vitro, this agent is promising for further evaluation in vivo in breast cancer xenografts.

\section{Triple-Negative Breast Cancer}

One potential strategy to overcome drug resistance in TNBC is to combine mAbs with therapeutic radionuclides. Nimotuzumab is a mAb that binds to EGFR and clinically used in several countries for the treatment of epithelial-derived tumors that overexpress EGFR (Mazorra et al., 2018). In one recent study, ${ }^{111} \mathrm{In}-\mathrm{Bn}$ DTPA-nimotuzumab (Antibodies, Figure 2) was prepared by conjugating nimotuzumab to benzyl isothiocyanate DTPA (BnDTPA) and radiolabeling with ${ }^{111}$ In, and evaluated in MDA-MB468 xenograft models (Chan et al., 2020). Therapeutic efficacy was demonstrated by its enhanced inhibition of tumor growth, where the tumor doubling ratio of MDA-MB-468 xenografts was about 2-fold longer than those treated with the unlabeled BnDTPA-nimotuzumab or saline. ${ }^{111}$ In-Bn-DTPA-nimotuzumab may provide an alternative strategy for targeted treatment of TNBC. This approach might be beneficial to the basal-like subtype of TNBC, whose gene expression profiles suggest sensitivity to therapies that employ DNA damage mechanisms (Lehmann et al., 2011).

Prostate-specific membrane antigen (PSMA) is an established target for theranostics of prostate cancer, but a potential new target for breast cancer. A recent study reported that PSMA was expressed in tumor cells and tumor-associated neovasculature of primary breast cancer and distant metastases, while normal breast tissues expressed PSMA only in the glandular cells (Kasoha et al., 2017). One recent study evaluated the efficacy of radiolabeled PSMA-ligand in TNBC models (Morgenroth et al., 2019). High specific tumor uptake of ${ }^{68} \mathrm{Ga}$-PSMA-11 was shown in MDA-

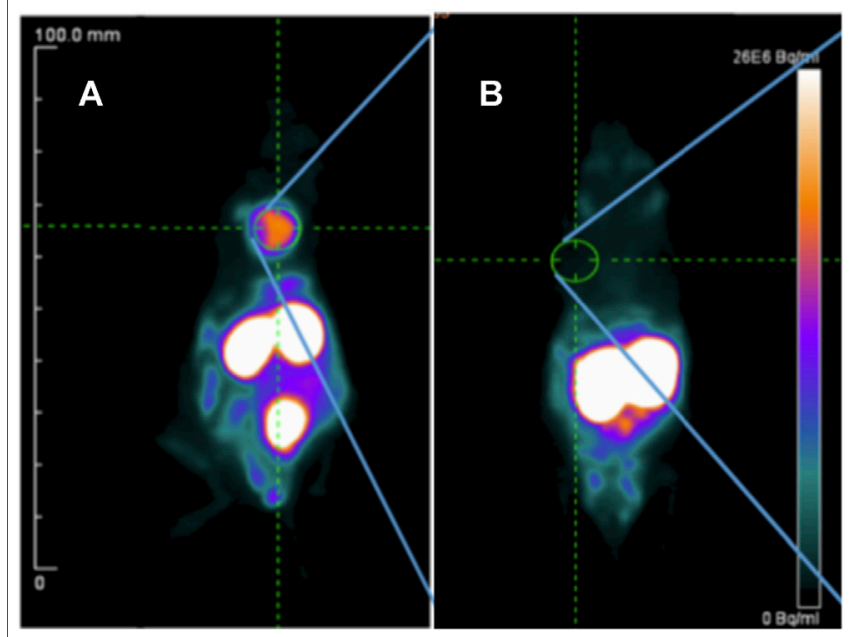

FIGURE 6 | PET imaging of ${ }^{68} \mathrm{Ga}-\mathrm{PSMA}-11$ in MDA-MB-231 (A) and MCF-7 (B) xenografts at 30 min post-injection (Morgenroth et al., 2019).

MB-231 xenografts with T/B ratio of $43.3 \pm 0.9$ at $30 \mathrm{~min}$ p. i., while tumor uptake in the control MCF-7 xenografts was negligible, with $\mathrm{T} / \mathrm{B}$ ratio of $1.1 \pm 0.1$ (Figure 6). The MDAMB-231 cells showed a high pro-angiogenic potential on tube formation of endothelial huvec cells. ${ }^{177} \mathrm{Lu}-\mathrm{PSMA}-617$ strongly impaired the vitality and angiogenic potential of MDA-MB -231 medium-conditioned HUVEC cells. This study presented the rationale for PSMA-targeted therapy for TNBC.

\section{Subtype-Independent Therapy Agents}

The peptide-receptor radionuclide therapy (PRRT) is an approach that uses radiolabeled peptides that bind to receptors on the surface of cancer cells for specific delivery of ionizing radiation. Since GRPR are overexpressed across all subtypes of breast cancer, PRRT of GRPR might have a more general application for breast cancer treatment. To increase the stability of the targeting peptide, nanoparticles have been increasingly used as drug delivery vehicles. A nanosystem based on the ${ }^{177}$ Lu-labeled polyamidoamine (PAMAM) dendrimer (DN) loaded with paclitaxel (PTX) and functionalized on the surface with the DOTA-BBN peptide was designed for specific targeting to GRPR in T47D breast cancer xenografts (Gibbens-Bandala et al., 2019a). The ${ }^{177} \mathrm{Lu}-$ DOTA-DN(PTX)-BBN nanoconjugate had significant uptake and internalization in T47D cells, with an estimated absorbed radiation dose of $3.0 \mathrm{~Gy} / \mathrm{MBq}$ at infinite time. Tumor uptake of ${ }^{177} \mathrm{Lu}-\mathrm{DOTA}-\mathrm{DN}(\mathrm{PTX})-\mathrm{BBN}$ was about $35 \% \mathrm{ID} / \mathrm{g}$ at $120 \mathrm{~h} \mathrm{p}$. i., with a corresponding reduction in tumor volume by $16 \%$ (Figure 7). Another nanoparticle, poly lactic-co-glycolic acid (PLGA), was also evaluated for delivery of drugs and radiation (Gibbens-Bandala et al., 2019b). A PTX-loaded PLGA was conjugated to DOTA-BBN, labeled with ${ }^{177} \mathrm{Lu}$, and tested in MDA-MB-231 xenografts. The ${ }^{177}$ Lu-BBN-PLGA (PTX) treated group showed the lowest tumor proliferation and strongest inhibition of tumor growth among the other control groups. The average absorbed radiation dose in the tumor was $37 \pm$ 


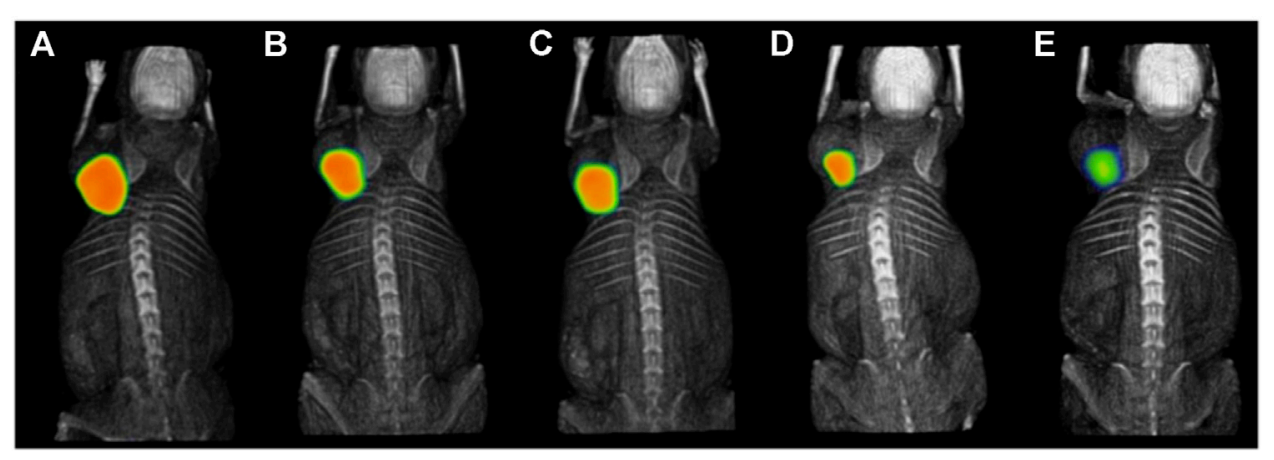

FIGURE 7 | Intratumoral administration of ${ }^{177}$ Lu-DOTA-DN(PTX)-BN after $1.5 \mathrm{~h}$ (A), $9 \mathrm{~h}$ (B), $10 \mathrm{~h}$ (C), $24 \mathrm{~h}$ (D), and $120 \mathrm{~h}$ (E) in T47D xenograft model (GibbensBandala et al., 2019a). The general structure of ${ }^{177}$ Lu-DOTA-DN(PTX)-BN was shown in Figure 2 I.

7.0 Gy. These two nanosystems both exhibited enhanced therapeutic efficacy due to $\beta$-radiation from ${ }^{177} \mathrm{Lu}$ and controlled release of PTX. Another example of ${ }^{177} \mathrm{Lu}$-labeled nanosystem is a dendrimer conjugated to folate and BBN with gold nanoparticles in the dendritic cavity (Mendoza-Nava et al., 2017). The bispecific ${ }^{177}$ Lu-DenAuNP-FA-BBN showed high absorbed radiation dose with $63 \pm 4.2 \mathrm{~Gy}$ delivered to T47D cells. Further studies are needed to evaluate its therapeutic efficacy in vivo. Taken together, these strategies of using ${ }^{177} \mathrm{Lu}-$ labeled chemotherapeutic drug-loaded nanosystems with BBN peptides for combined targeted therapy have shown promise in their application to GRPR-positive breast cancers.

Besides the classic breast cancer targets, such as ER, PR, HER2, EGFR, and recently, GRPR, other targets such as FA and nucleolin have also shown some promise for theranostics of breast cancer. A drug delivery nanosystem based on ${ }^{99 \mathrm{~m}} \mathrm{Tc}$ labeled 5-fluorouracil (5-FU)-loaded and FA-functionalized PAMAM G4 dendrimer ( ${ }^{99 \mathrm{~m}}$ Tc-PEG-PAMAM G4-FA-5FU) was designed for chemotherapy delivery to FA-overexpressing tumors with ${ }^{99 \mathrm{~m}} \mathrm{Tc}$ serving as the SPECT reporter for this treatment, and high tumor uptake of the agent in MCF-7 xenografts (Narmani et al., 2017).

An ${ }^{111}$ In-labeled F3 peptide (Peptides, Figure 2), which is a fragment of the human high mobility group protein 2binding nucleolin, was developed to investigate the Auger electron-targeted radiotherapy in HER2-positive breast cancer xenograft models (Cornelissen et al., 2012). Animal treated with ${ }^{111}$ In-BnDTPA-F3 showed significantly slower tumor growth and longer survival time. SPECT imaging is feasible with this agent.

\section{DISCUSSION AND PERSPECTIVES}

In the era of precision medicine, theranostic agents are becoming increasingly important for selecting breast cancer patients most likely to benefit from targeted treatments through imaging and offering more options for effective treatments in this heterogenous disease. In this review, we highlight many imaging probes for novel targets with potential for translation to clinical studies. Among the different targets discussed for breast cancer imaging, the GRPR is the most promising novel target in our opinion. GRPR is reported to be overexpressed in $96 \%$ of breast cancer tissues across all molecular subtypes of breast cancer. The GRPR-targeted agents for both imaging and therapy achieved excellent tumor uptake, such as ${ }^{111}$ In-JMV4168 for luminal-subtype imaging (Dalm et al., 2015), ${ }^{68} \mathrm{Ga}$-NOTAPEG $_{3}$-RM26 for HER2-subtype imaging (Varasteh et al., 2014), ${ }^{99 m}$ Tc-BN4 for TNBC imaging (De et al., 2019), ${ }^{177} \mathrm{Lu}-\mathrm{DOTA}-$ $\mathrm{DN}$ (PTX)-BN for luminal-subtype therapy (Gibbens-Bandala et al., 2019a), and ${ }^{177}$ Lu-BN-PLGA (PTX) for TNBC therapy (Gibbens-Bandala et al., 2019b). These independent studies indicate that GRPR is a highly promising target for theranostics of breast cancer.

Additionally, there are many targeted small molecule inhibitors under clinical trials for the treatment of breast cancer, such as the CDK4/6 inhibitor palbociclib (Song et al., 2019; Gan et al., 2020; Ramos et al., 2020), the PI3K/Akt/mTOR pathway inhibitor pictilisib (Altine et al., 2019; Han et al., 2019), the HDAC inhibitor CUDC-101 (Meng et al., 2013). The radiolabeled analogs of these small molecule inhibitors that we described in this review showed high tumor uptake in breast cancer xenografts. These agents may provide a non-invasive diagnostic imaging tool to monitor the responses to their therapeutic equivalents.

Recently, dual-receptor targeted strategies have attracted increasing attention in heterogeneous subtypes of breast cancer imaging within primary and metastatic lesions. One of the reasons for their success is that bispecific constructs targeting two receptors can help to overcome drug resistance associated with mono-targeted therapies (Thakur et al., 2018). Different bispecific imaging and/or theranostic agents have also been developed, notably the scaffolds targeting GRPR/FA and EGFR/c-MET with ${ }^{99 \mathrm{~m}} \mathrm{Tc} /{ }^{177} \mathrm{Lu}-\mathrm{BBN}-\mathrm{FA}$ (Aranda-Lara et al., 2016a; Aranda-Lara et al., 2016b) and [ $\left.{ }^{89} \mathrm{Zr}\right] \mathrm{ZrDFO}$ amivantamab (Cavaliere et al., 2020), respectively. These agents hold potential for clinical translation due to the high expression of targets in several molecular subtypes of breast cancer and the promise to overcome resistance to monotargeted therapy due to their multiple mechanisms of action. Overall, a significant progress has been made in pursing novel targets for breast cancer imaging. 
Although the studies mentioned above have shown promising results in rodent xenografts and in the setting of primary breast cancer, most of them did not focus on metastatic models. Of all the studies we reviewed, only ${ }^{68}$ Ga-NGR-RGD was evaluated in a lung metastasis model of breast cancer (Gai et al., 2020). The most typical sites of metastatic breast cancer are regional lymph nodes, bone, liver, lung, and brain (Jin et al., 2018). Hence, a good imaging agent should reach these organs, but there are still many challenges to overcome. For instance, a high liver uptake, commonly seen in PET and SPECT imaging with tracers that are metabolized in the liver, such as ${ }^{99 \mathrm{~m}}$ Tc-DTPA-estradiol (Xia et al., 2016), ${ }^{99 \mathrm{~m}} \mathrm{Tc}$-labeled palbociclib analogs ( ${ }^{99 \mathrm{~m}} \mathrm{Tc}-\mathrm{L} 2$ to $\mathrm{L} 5$ ) (Song et al., 2019), and ${ }^{11}$ C-pictilisib (Han et al., 2019), may be insensitive in detecting liver metastasis. Thus, future studies should make more efforts into evaluating imaging agents in the metastatic setting.

Crossing the blood-brain barrier (BBB) represents another dilemma for detecting brain metastasis. The BBB with its tight junctions limits the passage of large molecules from the blood to the brain (Deeken and Löscher, 2007). In addition, there are various efflux transporters expressed in the $\mathrm{BBB}$, including P-glycoprotein and breast cancer resistance protein, which contribute to restrict the entry of potentially therapeutic agents (de Vries et al., 2007). A recent study reported that trastuzumab conjugated with melanotransferrin may help treat brain metastasis, and melanotransferrin may be a potential delivery vehicle to increase antibody transport across the BBB (Nounou et al., 2016).

A limitation of the preclinical studies we introduced above is that they all used animal xenograft models due to poor or no cross-reactivity to mouse antigens. While these animal models allow for a convenient method to determine specificity in vivo for human targets, they do not capture accurate biodistribution to normal organs, which pose challenges with using rodents for dosimetry estimates for clinical translation. Nevertheless, companion imaging agents such as those described in this review have the potential to predict and monitor response to treatment, especially for the diverse molecular subtypes in breast cancer. The preclinical studies described in this review showed promising results of targeted imaging in breast cancer xenografts. Validation in human studies warrants further investigation.

With regard to TRT, ${ }^{177} \mathrm{Lu}$ is a widely used radionuclide due to its relatively long-range in tissues (Massicano et al., 2018), which allows a cross-fire effect with the surrounding cells into the tumor. ${ }^{111}$ In can exhibit high therapeutic efficacy after being delivered to the tumor cell nucleus to maximize the cell-killing ability with the methods of attaching nuclear localization sequence (NLS) peptides, such as ${ }^{111}$ InNLS-trastuzumab (Costantini et al., 2010), and co-administration

\section{REFERENCES}

Altine, B., Gai, Y., Han, N., Jiang, Y., Ji, H., Fang, H., et al. (2019). Preclinical evaluation of a fluorine-18 $\left({ }^{18} \mathrm{~F}\right)$-Labeled phosphatidylinositol 3-kinase inhibitor for breast cancer imaging. Mol. Pharmaceutics 16 (11), 4563-4571. doi:10.1021/ acs.molpharmaceut.9b00690 with other pharmaceuticals including mAbs such as ${ }^{111} \mathrm{In}-\mathrm{Bn}$-DTPAnimotuzumab (Chan et al., 2020).

Another useful tool for drug delivery is nanosystems, especially to deliver chemotherapeutic drugs, mAbs, or their combination, such as ${ }^{111}$ In-trastuzumab-DOX-SPIONs (Zolata et al., 2015), ${ }^{177} \mathrm{Lu}$-AuNPs-trastuzumab-panitumumab (Yook et al., 2020), and ${ }^{177} \mathrm{Lu}-\mathrm{DOTA}-\mathrm{DN}(\mathrm{PTX})-\mathrm{BBN}$ (GibbensBandala et al., 2019a). TRT combined with chemotherapy or antibodies have proven to be beneficial to breast cancer treatment. Although the tumor uptake and absorbed radiation dose might vary considerably between different patients, precision medicine for breast cancer patients may help to make TRT more effective and reduce normal tissue toxicity.

\section{CONCLUSION}

Targeted imaging and therapy using nuclear medicine methods show promise for precision medicine for patients with breast cancer. Molecular imaging can help with diagnosis, staging, guiding treatment, and predicting response to corresponding targeted therapy. Many studies discussed here have made great contributions in the investigation of new strategies and new agents for breast cancer imaging and therapy. A series of new targets have been found to be valuable for potentially overcoming resistance to standard of care treatments. These new investigations are inspiring in preclinical studies. We look forward to seeing more studies advance to clinical trials in the near future.

\section{DATA AVAILABILITY STATEMENT}

The original contributions presented in the study are included in the article/Supplementary Material, further inquiries can be directed to the corresponding author.

\section{AUTHOR CONTRIBUTIONS}

HF, AC, and ZL wrote and edited the manuscript. YH and BM-N edited the manuscript. All authors read and approved the final manuscript.

\section{FUNDING}

HF is supported by the China Scholarship Council (No. 201906160034).

Andersson, K. G., Rosestedt, M., Varasteh, Z., Malm, M., Sandström, M., Tolmachev, V., et al. (2015). Comparative evaluation of ${ }^{111}$ In-labeled NOTA-conjugated affibody molecules for visualization of HER3 expression in malignant tumors. Oncol. Rep. 34 (2), 1042-1048. doi:10. 3892/or.2015.4046

Apostolopoulos, V., Pietersz, G. A., Tsibanis, A., Tsikkinis, A., Drakaki, H., Loveland, B. E., et al. (2006). Pilot phase III immunotherapy study in early- 
stage breast cancer patients using oxidized mannan-MUC1 [ISRCTN71711835]. Breast Cancer Res. 8 (3), R27. doi:10.1186/bcr1505

Aranda-Lara, L., Ferro-Flores, G., Azorín-Vega, E., Ramírez, F. d. M., JiménezMancilla, N., Ocampo-García, B., et al. (2016a). Synthesis and evaluation of Lys 1 (a, $\gamma$-Folate)Lys $3\left({ }^{177}\right.$ Lu-DOTA)-Bombesin(1-14) as a potential theranostic radiopharmaceutical for breast cancer. Appl. Radiat. Isot. 107, 214-219. doi:10. 1016/j.apradiso.2015.10.030

Aranda-Lara, L., Ferro-Flores, G., Ramírez, F. d. M., Ocampo-García, B., SantosCuevas, C., Díaz-Nieto, L., et al. (2016b). Improved radiopharmaceutical based on ${ }^{99 \mathrm{~m}} \mathrm{Tc}$-Bombesin-folate for breast tumour imaging. Nucl. Med. Commun. 37 (4), 377-386. doi:10.1097/mnm.0000000000000460

Bader, A. G., Kang, S., Zhao, L., and Vogt, P. K. (2005). Oncogenic PI3K deregulates transcription and translation. Nat. Rev. Cancer 5 (12), 921-929. doi: $10.1038 / \mathrm{nrc1} 753$

Bailey, K. E., Costantini, D. L., Cai, Z., Scollard, D. A., Chen, Z., Reilly, R. M., et al. (2007). Epidermal growth factor receptor inhibition modulates the nuclear localization and cytotoxicity of the Auger electron emitting radiopharmaceutical ${ }^{111}$ In-DTPA human epidermal growth factor. J. Nucl. Med. 48 (9), 1562-1570. doi:10.2967/jnumed.107.044073

Baratto, L., Duan, H., Mäcke, H., and Iagaru, A. (2020). Imaging the distribution of gastrin-releasing peptide receptors in cancer. J. Nucl. Med. 61 (6), 792-798. doi:10.2967/jnumed.119.234971

Bardia, A., Mayer, I. A., Vahdat, L. T., Tolaney, S. M., Isakoff, S. J., Diamond, J. R., et al. (2019). Sacituzumab govitecan-hziy in refractory metastatic triplenegative breast cancer. N. Engl. J. Med. 380 (8), 741-751. doi:10.1056/ NEJMoa 1814213

Bianchini, G., Balko, J. M., Mayer, I. A., Sanders, M. E., and Gianni, L. (2016). Triple-negative breast cancer: challenges and opportunities of a heterogeneous disease. Nat. Rev. Clin. Oncol. 13 (11), 674-690. doi:10.1038/nrclinonc.2016.66

Blasco-Benito, S., Seijo-Vila, M., Caro-Villalobos, M., Tundidor, I., Andradas, C., García-Taboada, E., et al. (2018). Appraising the "entourage effect": antitumor action of a pure cannabinoid versus a botanical drug preparation in preclinical models of breast cancer. Biochem. Pharmacol. 157, 285-293. doi:10.1016/j.bcp. 2018.06.025

Bolden, J. E., Peart, M. J., and Johnstone, R. W. (2006). Anticancer activities of histone deacetylase inhibitors. Nat. Rev. Drug Discov. 5 (9), 769-784. doi:10. $1038 / \mathrm{nrd} 2133$

Boswell, C. A., and Brechbiel, M. W. (2005). Auger electrons: lethal, low energy, and coming soon to a tumor cell nucleus near you. J. Nucl. Med. 46 (12), 1946-1947.

Bottai, G., Truffi, M., Corsi, F., and Santarpia, L. (2017). Progress in nonviral gene therapy for breast cancer and what comes next? Expert Opin. Biol. Ther. 17 (5), 595-611. doi:10.1080/14712598.2017.1305351

Bouchalova, K., Svoboda, M., Kharaishvili, G., Vrbkova, J., Bouchal, J., Trojanec, R., et al. (2015). BCL2 is an independent predictor of outcome in basal-like triple-negative breast cancers treated with adjuvant anthracycline-based chemotherapy. Tumor Biol. 36 (6), 4243-4252. doi:10.1007/s13277-015-3061-7

Callander, N. S., Varki, N., and Vijaya Rao, L. M. (1992). Immunohistochemical identification of tissue factor in solid tumors. Cancer 70 (5), 1194-1201. doi:10. 1002/1097-0142(19920901)70:5<1194::aid-cncr2820700528>3.0.co;2-e

Cancer-Genome-Atlas-Network (2012). Comprehensive molecular portraits of human breast tumours. Nature 490 (7418), 61-70. doi:10.1038/nature11412

Carey, J. P. W., Karakas, C., Bui, T., Chen, X., Vijayaraghavan, S., Zhao, Y., et al. (2018). Synthetic lethality of PARP inhibitors in combination with MYC blockade is independent of BRCA status in triple-negative breast cancer. Cancer Res. 78 (3), 742-757. doi:10.1158/0008-5472.CAN-17-1494

Cavaliere, A., Sun, S., Lee, S., Bodner, J., Li, Z., Huang, Y., et al. (2020). Development of $\left[{ }^{89} \mathrm{Zr}\right] \mathrm{ZrDFO}$-amivantamab bispecific to EGFR and c-MET for PET imaging of triple-negative breast cancer. Eur. J. Nucl. Med. Mol. Imaging 48, 383. doi:10.1007/s00259-020-04978-6

Chae, Y. K., Gagliato, D. d. M., Pai, S. G., Carneiro, B., Mohindra, N., Giles, F. J., et al. (2016). The association between EGFR and cMET expression and phosphorylation and its prognostic implication in patients with breast cancer. PLoS One 11 (4), e0152585. doi:10.1371/journal.pone.0152585

Chan, C., Fonge, H., Lam, K., and Reilly, R. M. (2020). Effectiveness and normal tissue toxicity of Auger electron (AE) radioimmunotherapy (RIT) with $\left[{ }^{111} \mathrm{In}\right]$ In-Bn-DTPA-nimotuzumab in mice with triple-negative or trastuzumab- resistant human breast cancer xenografts that overexpress EGFR. Nucl. Med. Biol. 80-81, 37-44. doi:10.1016/j.nucmedbio.2019.10.001

Chen, X., Mangala, L. S., Rodriguez-Aguayo, C., Kong, X., Lopez-Berestein, G., and Sood, A. K. (2018). RNA interference-based therapy and its delivery systems. Cancer Metastasis Rev. 37 (1), 107-124. doi:10.1007/s10555-017-9717-6

Chun, K.-H., Park, J. H., and Fan, S. (2017). Predicting and overcoming chemotherapeutic resistance in breast cancer. Adv. Exp. Med. Biol. 1026, 59-104. doi:10.1007/978-981-10-6020-5_4

Cooper, T. M., Sison, E. A. R., Baker, S. D., Li, L., Ahmed, A., Trippett, T., et al. (2017). A phase 1 study of the CXCR4 antagonist plerixafor in combination with high-dose cytarabine and etoposide in children with relapsed or refractory acute leukemias or myelodysplastic syndrome: a Pediatric Oncology Experimental Therapeutics Investigators' Co. Pediatr. Blood Cancer 64 (8), e26414. doi:10.1002/pbc.26414

Cornelissen, B., Waller, A., Target, C., Kersemans, V., Smart, S., and Vallis, K. A. (2012). ${ }^{111}$ In-BnDTPA-F3: an Auger electron-emitting radiotherapeutic agent that targets nucleolin. EJNMMI Res. 2, 9. doi:10.1186/2191-219X-2-9

Costantini, D. L., McLarty, K., Lee, H., Done, S. J., Vallis, K. A., and Reilly, R. M. (2010). Antitumor effects and normal-tissue toxicity of ${ }^{111}$ In-nuclear localization sequence-trastuzumab in athymic mice bearing HER-positive human breast cancer xenografts. J. Nucl. Med. 51 (7), 1084-1091. doi:10. 2967/jnumed.109.072389

Cowherd, S., Miller, L. D., Melin, S. A., Akman, S., Isom, S., Cole, J., et al. (2015). A phase II clinical trial of weekly paclitaxel and carboplatin in combination with panitumumab in metastatic triple negative breast cancer. Cancer Biol. Ther. 16 (5), 678-683. doi:10.1080/15384047.2015.1026481

Cyprian, F. S., Akhtar, S., Gatalica, Z., and Vranic, S. (2019). Targeted immunotherapy with a checkpoint inhibitor in combination with chemotherapy: a new clinical paradigm in the treatment of triple-negative breast cancer. Bosn J. Basic Med. Sci. 19 (3), 227-233. doi:10.17305/bjbms.2019.4204

Dahle, J., Borrebæk, J., Jonasdottir, T. J., Hjelmerud, A. K., Melhus, K. B., Bruland, $\varnothing$. S., et al. (2007). Targeted cancer therapy with a novel low-dose rate a-emitting radioimmunoconjugate. Blood 110 (6), 2049-2056. doi:10.1182/ blood-2007-01-066803

Dahr, S. S., Cusick, M., Rodriguez-Coleman, H., Srivastava, S. K., Thompson, D. J., Linehan, W. M., et al. (2007). Intravitreal anti-vascular endothelial growth factor therapy with pegaptanib for advanced von Hippel-Lindau disease of the retina. Retina 27 (2), 150-158. doi:10.1097/IAE.0b013e318030a290

Dai, X., Cheng, H., Bai, Z., and Li, J. (2017). Breast cancer cell line classification and its relevance with breast tumor subtyping. J. Cancer 8 (16), 3131-3141. doi:10. $7150 /$ jca. 18457

Dalm, S. U., Martens, J. W. M., Sieuwerts, A. M., van Deurzen, C. H. M., Koelewijn, S. J., de Blois, E., et al. (2015). In vitro and in vivo application of radiolabeled gastrin-releasing peptide receptor ligands in breast cancer. J. Nucl. Med. 56 (5), 752-757. doi:10.2967/jnumed.114.153023

De, K., Mukherjee, D., Sinha, S., and Ganguly, S. (2019). HYNIC and DOMA conjugated radiolabeled bombesin analogs as receptor-targeted probes for scintigraphic detection of breast tumor. EJNMMI Res. 9 (1), 25. doi:10.1186/ s13550-019-0493-x

de Vries, E. G. E., Kist de Ruijter, L., Lub-de Hooge, M. N., Dierckx, R. A., Elias, S. G., and Oosting, S. F. (2019). Integrating molecular nuclear imaging in clinical research to improve anticancer therapy. Nat. Rev. Clin. Oncol. 16 (4), 241-255. doi:10.1038/s41571-018-0123-y

de Vries, N. A., Zhao, J., Kroon, E., Buckle, T., Beijnen, J. H., and van Tellingen, O. (2007). P-glycoprotein and breast cancer resistance protein: two dominant transporters working together in limiting the brain penetration of topotecan. Clin. Cancer Res. 13 (21), 6440-6449. doi:10.1158/1078-0432.CCR-07-1335

Debordeaux, F., Chansel-Debordeaux, L., Pinaquy, J.-B., Fernandez, P., and Schulz, J. (2018). What about $\alpha v \beta 3$ integrins in molecular imaging in oncology? Nucl. Med. Biol. 62-63, 31-46. doi:10.1016/j.nucmedbio.2018.04.006

Deeken, J. F., and Löscher, W. (2007). The blood-brain barrier and cancer: transporters, treatment, and Trojan horses. Clin. Cancer Res. 13 (6), 1663-1674. doi:10.1158/1078-0432.CCR-06-2854

Doran, M. G., Carnazza, K. E., Steckler, J. M., Spratt, D. E., Truillet, C., Wongvipat, J., et al. (2016). Applying ${ }^{89} \mathrm{Zr}$-transferrin to study the pharmacology of inhibitors to BET bromodomain containing proteins. Mol. Pharmaceutics 13 (2), 683-688. doi:10.1021/acs.molpharmaceut.5b00882 
Dua, R., Zhang, J., Nhonthachit, P., Penuel, E., Petropoulos, C., and Parry, G. (2010). EGFR over-expression and activation in high HER2, ER negative breast cancer cell line induces trastuzumab resistance. Breast Cancer Res. Treat. 122 (3), 685-697. doi:10.1007/s10549-009-0592-x

Ehlerding, E. B., Sun, L., Lan, X., Zeng, D., and Cai, W. (2018). Dual-targeted molecular imaging of cancer. J. Nucl. Med. 59 (3), 390-395. doi:10.2967/ jnumed.117.199877

Erdmann, S., Niederstadt, L., Koziolek, E. J., Gómez, J. D. C., Prasad, S., Wagener, A., et al. (2019). CMKLR1-targeting peptide tracers for PET/MR imaging of breast cancer. Theranostics 9 (22), 6719-6733. doi:10.7150/thno.34857

Erspamer, V., Erspamer, G. F., and Inselvini, M. (1970). Some pharmacological actions of alytesin and bombesin. J. Pharm. Pharmacol. 22 (11), 875-876. doi:10.1111/j.2042-7158.1970.tb08465.x

Eyetech-Study-Group (2002). Preclinical and phase 1A clinical evaluation of an anti-VEGF pegylated aptamer (EYE001) for the treatment of exudative agerelated macular degeneration. Retina (Philadelphia, Pa) 22 (2), 143-152. doi:10. 1097/00006982-200204000-00002

Falkenberg, K. J., and Johnstone, R. W. (2014). Histone deacetylases and their inhibitors in cancer, neurological diseases and immune disorders. Nat. Rev. Drug Discov. 13 (9), 673-691. doi:10.1038/nrd4360

Finn, R. S., Martin, M., Rugo, H. S., Jones, S., Im, S.-A., Gelmon, K., et al. (2016). Palbociclib and letrozole in advanced breast cancer. N. Engl. J. Med. 375 (20), 1925-1936. doi:10.1056/NEJMoa1607303

Frigerio, B., Bizzoni, C., Jansen, G., Leamon, C. P., Peters, G. J., Low, P. S., et al. (2019). Folate receptors and transporters: biological role and diagnostic/ therapeutic targets in cancer and other diseases. J. Exp. Clin. Cancer Res. 38 (1), 125. doi:10.1186/s13046-019-1123-1

Fu, P., Shen, B., Zhao, C., and Tian, G. (2010). Molecular imaging of MDM2 messenger RNA with ${ }^{99 \mathrm{~m}} \mathrm{Tc}$-labeled antisense oligonucleotides in experimental human breast cancer xenografts. J. Nucl. Med. 51 (11), 1805-1812. doi:10.2967/ jnumed.110.077982

Fu, P., Tian, L., Cao, X., Li, L., Xu, P., and Zhao, C. (2016). Imaging CXCR4 expression with ${ }^{99 \mathrm{~m}} \mathrm{Tc}$-radiolabeled small-interference RNA in experimental human breast cancer xenografts. Mol. Imaging Biol. 18 (3), 353-359. doi:10. 1007/s11307-015-0899-4

Gai, Y., Jiang, Y., Long, Y., Sun, L., Liu, Q., Qin, C., et al. (2020). Evaluation of an integrin $\operatorname{av} \beta 3$ and aminopeptidase $\mathrm{N}$ dual-receptor targeting tracer for breast cancer imaging. Mol. Pharmaceutics 17 (1), 349-358. doi:10.1021/acs. molpharmaceut.9b01134

Gan, Q., Song, X., Zhang, X., and Zhang, J. (2020). Preparation and evaluation of ${ }^{99 \mathrm{~m}} \mathrm{Tc}$-labeled HYNIC-palbociclib analogs for cyclin-dependent kinase 4/6positive tumor imaging. Eur. J. Med. Chem. 188, 112032. doi:10.1016/j.ejmech. 2019.112032

Gangangari, K. K., Váradi, A., Majumdar, S., Larson, S. M., Pasternak, G. W., and Pillarsetty, N. K. (2020). Imaging sigma-1 receptor (S1R) expression using iodine-124-labeled 1-(4-Iodophenyl)-3-(2-adamantyl)guanidine ([ $\left.\left.{ }^{124} \mathrm{I}\right] \mathrm{IPAG}\right)$. Mol. Imaging Biol. 22 (2), 358-366. doi:10.1007/s11307-019-01369-8

Gherasim, C., Lofgren, M., and Banerjee, R. (2013). Navigating the B12 road: assimilation, delivery, and disorders of cobalamin. J. Biol. Chem. 288 (19), 13186-13193. doi:10.1074/jbc.R113.458810

Ghobrial, I. M., Liu, C. J., Zavidij, O., Azab, A. K., Baz, R., Laubach, J. P., et al. (2019). Phase I/II trial of the CXCR4 inhibitor plerixafor in combination with bortezomib as a chemosensitization strategy in relapsed/refractory multiple myeloma. Am. J. Hematol. 94 (11), 1244-1253. doi:10.1002/ajh.25627

Gibbens-Bandala, B., Morales-Avila, E., Ferro-Flores, G., Santos-Cuevas, C., LunaGutiérrez, M., Ramírez-Nava, G., et al. (2019a). Synthesis and evaluation of ${ }^{177} \mathrm{Lu}$-DOTA-DN(PTX)-BN for selective and concomitant radio and drugtherapeutic effect on breast cancer cells. Polymers 11 (10), 1572. doi:10.3390/ polym 11101572

Gibbens-Bandala, B., Morales-Avila, E., Ferro-Flores, G., Santos-Cuevas, C., Meléndez-Alafort, L., Trujillo-Nolasco, M., et al. (2019b). ${ }^{177} \mathrm{Lu}$-BombesinPLGA (paclitaxel): a targeted controlled-release nanomedicine for bimodal therapy of breast cancerLu-Bombesin-PLGA (paclitaxel): a targeted controlledrelease nanomedicine for bimodal therapy of breast cancer. Mater. Sci. Eng. C 105, 110043. doi:10.1016/j.msec.2019.110043

Gill, M. R., Falzone, N., Du, Y., and Vallis, K. A. (2017). Targeted radionuclide therapy in combined-modality regimens. Lancet Oncol. 18 (7), e414-e423. doi:10.1016/S1470-2045(17)30379-0
Goodman, S. L., and Picard, M. (2012). Integrins as therapeutic targets. Trends Pharmacol. Sci. 33 (7), 405-412. doi:10.1016/j.tips.2012.04.002

Graat, H. C. A., Carette, J. E., Schagen, F. H. E., Vassilev, L. T., Gerritsen, W. R., Kaspers, G. J. L., et al. (2007). Enhanced tumor cell kill by combined treatment with a small-molecule antagonist of mouse double minute 2 and adenoviruses encoding p53. Mol. Cancer Ther. 6 (5), 1552-1561. doi:10.1158/1535-7163. MCT-06-0631

Halmos, G., Wittliff, J. L., and Schally, A. V. (1995). Characterization of bombesin/ gastrin-releasing peptide receptors in human breast cancer and their relationship to steroid receptor expression. Cancer Res. 55 (2), 280-287.

Han, N., Jiang, Y., Gai, Y., Liu, Q., Yuan, L., Wang, Y., et al. (2019). ${ }^{11}$ C-Labeled pictilisib (GDC-0941) as a molecular tracer targeting phosphatidylinositol 3kinase (PI3K) for breast cancer imaging. Contrast Media Mol. Imaging 2019, 1. doi:10.1155/2019/17601842019

Haupt, S., Vijayakumaran, R., Miranda, P. J., Burgess, A., Lim, E., and Haupt, Y. (2017). The role of MDM2 and MDM4 in breast cancer development and prevention. J. Mol. Cel Biol 9 (1), 53-61. doi:10.1093/jmcb/mjx007

He, M. Y., Rancoule, C., Rehailia-Blanchard, A., Espenel, S., Trone, J.-C., Bernichon, E., et al. (2018). Radiotherapy in triple-negative breast cancer: current situation and upcoming strategies. Crit. Rev. Oncology/Hematology 131, 96-101. doi:10.1016/j.critrevonc.2018.09.004

Henry, K. E., Dilling, T. R., Abdel-Atti, D., Edwards, K. J., Evans, M. J., and Lewis, J. S. (2018). Noninvasive ${ }^{89} \mathrm{Zr}$-transferrin PET shows improved tumor targeting compared with ${ }^{18} \mathrm{~F}$-FDG PET in MYC-overexpressing human triple-negative breast cancer. J. Nucl. Med. 59 (1), 51-57. doi:10.2967/jnumed.117.192286

Holland, J. P., Evans, M. J., Rice, S. L., Wongvipat, J., Sawyers, C. L., and Lewis, J. S. (2012). Annotating MYC status with ${ }^{89} \mathrm{Zr}$-transferrin imaging. Nat. Med. 18 (10), 1586-1591. doi:10.1038/nm.2935

Horiuchi, D., Anderton, B., and Goga, A. (2014). Taking on challenging targets: making MYC druggable. Am. Soc. Clin. Oncol. Educ. Book, e497-e502. doi:10. 14694/EdBook_AM.2014.34.e497

Horiuchi, D., Kusdra, L., Huskey, N. E., Chandriani, S., Lenburg, M. E., GonzalezAngulo, A. M., et al. (2012). MYC pathway activation in triple-negative breast cancer is synthetic lethal with CDK inhibition. J. Exp. Med. 209 (4), 679-696. doi:10.1084/jem.20111512

Hyman, D. M., Piha-Paul, S. A., Won, H., Rodon, J., Saura, C., Shapiro, G. I., et al. (2018). HER kinase inhibition in patients with HER2- and HER3-mutant cancers. Nature 554 (7691), 189-194. doi:10.1038/nature25475

Ibrahim, N. K., Yariz, K. O., Bondarenko, I., Manikhas, A., Semiglazov, V., Alyasova, A., et al. (2011). Randomized phase II trial of letrozole plus antiMUC1 antibody AS1402 in hormone receptor-positive locally advanced or metastatic breast cancer. Clin. Cancer Res. 17 (21), 6822-6830. doi:10.1158/ 1078-0432.CCR-11-1151

Ireson, C. R., and Kelland, L. R. (2006). Discovery and development of anticancer aptamers. Mol. Cancer Ther. 5 (12), 2957-2962. doi:10.1158/1535-7163.MCT06-0172

Jensen, R. T., Battey, J. F., Spindel, E. R., and Benya, R. V. (2008). International Union of Pharmacology. LXVIII. Mammalian bombesin receptors: nomenclature, distribution, pharmacology, signaling, and functions in normal and disease states. Pharmacol. Rev. 60 (1), 1-42. doi:10.1124/pr.107.07108

Jin, L., Han, B., Siegel, E., Cui, Y., Giuliano, A., and Cui, X. (2018). Breast cancer lung metastasis: molecular biology and therapeutic implications. Cancer Biol. Ther. 19 (10), 858-868. doi:10.1080/15384047.2018.1456599

Johnston, S., Basik, M., Hegg, R., Lausoontornsiri, W., Grzeda, L., Clemons, M., et al. (2016). Inhibition of EGFR, HER2, and HER3 signaling with AZD8931 in combination with anastrozole as an anticancer approach: phase II randomized study in women with endocrine-therapy-naïve advanced breast cancer. Breast Cancer Res. Treat. 160 (1), 91-99. doi:10.1007/s10549-016-3979-5

Karuppaiah, A., Rajan, R., Hariharan, S., Balasubramaniam, D. K., Gregory, M., and Sankar, V. (2020). Synthesis and characterization of folic acid conjugated Gemcitabine tethered silver nanoparticles (FA-GEM-AgNPs) for targeted delivery. Cpd 26 (26), 3141-3146. doi:10.2174/1381612826666200316143239

Kasoha, M., Unger, C., Solomayer, E.-F., Bohle, R. M., Zaharia, C., Khreich, F., et al. (2017). Prostate-specific membrane antigen (PSMA) expression in breast cancer and its metastases. Clin. Exp. Metastasis 34 (8), 479-490. doi:10. 1007/s10585-018-9878-x

Kato, M., Kitayama, J., Kazama, S., and Nagawa, H. (2003). Expression pattern of CXC chemokine receptor- 4 is correlated with lymph node metastasis in human 
invasive ductal carcinoma. Breast Cancer Res. 5 (5), R144-R150. doi:10.1186/ bcr627

Kebenko, M., Goebeler, M.-E., Wolf, M., Hasenburg, A., Seggewiss-Bernhardt, R., Ritter, B., et al. (2018). A multicenter phase 1 study of solitomab (MT110, AMG 110), a bispecific EpCAM/CD3 T-cell engager (BiTE) antibody construct, in patients with refractory solid tumors. Oncoimmunology 7 (8), e1450710. doi:10. 1080/2162402X.2018.1450710

Kim, H. J., Park, J. Y., Lee, T. S., Song, I. H., Cho, Y. L., Chae, J. R., et al. (2019). PET imaging of HER2 expression with an ${ }^{18} \mathrm{~F}$-fluoride labeled aptamer. PLoS One 14 (1), e0211047. doi:10.1371/journal.pone.0211047

Kim, M. J., Choi, J. R., Tae, N., Wi, T. M., Kim, K. M., Kim, D. H., et al. (2020). Novel antibodies targeting MUC1-C showed anti-metastasis and growthinhibitory effects on human breast cancer cells. Ijms 21 (9), 3258. doi:10. 3390/ijms21093258

Kircher, M., Herhaus, P., Schottelius, M., Buck, A. K., Werner, R. A., Wester, H.-J., et al. (2018). CXCR4-directed theranostics in oncology and inflammation. Ann. Nucl. Med. 32 (8), 503-511. doi:10.1007/s12149-018-1290-8

Kontermann, R. (2012). Dual targeting strategies with bispecific antibodies. MAbs 4 (2), 182-197. doi:10.4161/mabs.4.2.19000

Ku, A., Chan, C., Aghevlian, S., Cai, Z., Cescon, D., Bratman, S. V., et al. (2019a). MicroSPECT/CT imaging of cell-line and patient-derived EGFR-positive tumor xenografts in mice with panitumumab Fab modified with hexahistidine peptides to enable labeling with ${ }^{99 \mathrm{~m}} \mathrm{Tc}(\mathrm{I})$ tricarbonyl complex. Mol. Pharmaceutics 16 (8), 3559-3568. doi:10.1021/acs.molpharmaceut. $9 \mathrm{~b} 00422$

Ku, A., Facca, V. J., Cai, Z., and Reilly, R. M. (2019b). Auger electrons for cancer therapy - a review. EJNMMI Radiopharm. Chem. 4 (1), 27. doi:10.1186/s41181019-0075-2

Kuda-Wedagedara, A. N. W., Workinger, J. L., Nexo, E., Doyle, R. P., and ViolaVillegas, N. (2017). ${ }^{89} \mathrm{Zr}$-Cobalamin PET tracer: synthesis, cellular uptake, and use for tumor imaging. ACS Omega 2 (10), 6314-6320. doi:10.1021/acsomega. $7 \mathrm{~b} 01180$

Kumar, M., Salem, K., Tevaarwerk, A. J., Strigel, R. M., and Fowler, A. M. (2020). Recent advances in imaging steroid hormone receptors in breast cancer. J. Nucl. Med. 61 (2), 172-176. doi:10.2967/jnumed.119.228858

Kumar, P., Tripathi, S. K., Chen, C. P., Wickstrom, E., and Thakur, M. L. (2019). Evaluating Ga-68 peptide conjugates for targeting VPAC receptors: stability and pharmacokinetics. Mol. Imaging Biol. 21 (1), 130-139. doi:10.1007/s11307018-1207-x

Kwon, L. Y., Scollard, D. A., and Reilly, R. M. (2017). ${ }^{64} \mathrm{Cu}$-Labeled trastuzumab fab-PEG24-EGF radioimmunoconjugates bispecific for HER2 and EGFR: pharmacokinetics, biodistribution, and tumor imaging by PET in comparison to monospecific agents. Mol. Pharmaceutics 14 (2), 492-501. doi:10.1021/acs.molpharmaceut.6b00963

Labrijn, A. F., Janmaat, M. L., Reichert, J. M., and Parren, P. W. H. I. (2019). Bispecific antibodies: a mechanistic review of the pipeline. Nat. Rev. Drug Discov. 18 (8), 585-608. doi:10.1038/s41573-019-0028-1

Lee, K.-m., Giltnane, J. M., Balko, J. M., Schwarz, L. J., Guerrero-Zotano, A. L., Hutchinson, K. E., et al. (2017). MYC and MCL1 cooperatively promote chemotherapy-resistant breast cancer stem cells via regulation of mitochondrial oxidative phosphorylation. Cel Metab. 26 (4), 633-647. doi:10.1016/j.cmet.2017.09.009

Lee, Y., Lahens, N. F., Zhang, S., Bedont, J., Field, J. M., and Sehgal, A. (2019). G1/S cell cycle regulators mediate effects of circadian dysregulation on tumor growth and provide targets for timed anticancer treatment. Plos Biol. 17 (4), e3000228. doi:10.1371/journal.pbio.3000228

Lehmann, B. D., Bauer, J. A., Chen, X., Sanders, M. E., Chakravarthy, A. B., Shyr, Y., et al. (2011). Identification of human triple-negative breast cancer subtypes and preclinical models for selection of targeted therapies. J. Clin. Invest. 121 (7), 2750-2767. doi:10.1172/JCI45014

Liu, M., Wang, Z., Tan, T., Chen, Z., Mou, X., Yu, X., et al. (2018). An aptamerbased probe for molecular subtyping of breast cancer. Theranostics 8 (20), 5772-5783. doi:10.7150/thno. 28949

Lopez, J. S., and Banerji, U. (2017). Combine and conquer: challenges for targeted therapy combinations in early phase trials. Nat. Rev. Clin. Oncol. 14 (1), 57-66. doi:10.1038/nrclinonc.2016.96

LoRusso, P., Jänne, P. A., Oliveira, M., Rizvi, N., Malburg, L., Keedy, V., et al. (2013). Phase I study of U3-1287, a fully human anti-HER3 monoclonal antibody, in patients with advanced solid tumors. Clin. Cancer Res. 19 (11), 3078-3087. doi:10.1158/1078-0432.CCR-12-3051

Ma, R., Feng, Y., Lin, S., Chen, J., Lin, H., Liang, X., et al. (2015). Mechanisms involved in breast cancer liver metastasis. J. Transl Med. 13, 64. doi:10.1186/ s12967-015-0425-0

Maeda, T., Hiraki, M., Jin, C., Rajabi, H., Tagde, A., Alam, M., et al. (2018). MUC1$\mathrm{C}$ induces PD-L1 and immune evasion in triple-negative breast cancer. Cancer Res. 78 (1), 205-215. doi:10.1158/0008-5472.CAN-17-1636

Maher, C. M., Thomas, J. D., Haas, D. A., Longen, C. G., Oyer, H. M., Tong, J. Y., et al. (2018). Small-molecule Sigmal modulator induces autophagic degradation of PD-L1. Mol. Cancer Res. 16 (2), 243-255. doi:10.1158/15417786.MCR-17-0166

Masoud, V., and Pagès, G. (2017). Targeted therapies in breast cancer: new challenges to fight against resistance. Wjco 8 (2), 120-134. doi:10.5306/wjco. v8.i2.120

Massicano, A. V. F., Marquez-Nostra, B. V., and Lapi, S. E. (2018). Targeting HER2 in nuclear medicine for imaging and therapy. Mol. Imaging 17, 153601211774538. doi:10.1177/1536012117745386

Mazorra, Z., Chao, L., Lavastida, A., Sanchez, B., Ramos, M., Iznaga, N., et al. (2018). Nimotuzumab: beyond the EGFR signaling cascade inhibition. Semin. Oncol. 45 (1-2), 18-26. doi:10.1053/j.seminoncol.2018.04.008

McGuckin, M., Walsh, M. D., Hohn, B. G., Ward, B. G., and Wright, R. G. (1995). Prognostic significance of mucl epithelial mucin expression in breast cancer ${ }^{*}$. Hum. Pathol. 26 (4), 432-439. doi:10.1016/0046-8177(95) 90146-9

McGuire, A., Brown, J. A. L., and Kerin, M. J. (2015). Metastatic breast cancer: the potential of miRNA for diagnosis and treatment monitoring. Cancer Metastasis Rev. 34 (1), 145-155. doi:10.1007/s10555-015-9551-7

Mendoza-Nava, H., Ferro-Flores, G., Ramírez, F. d. M., Ocampo-García, B., Santos-Cuevas, C., Azorín-Vega, E., et al. (2017). Fluorescent, plasmonic, and radiotherapeutic properties of the ${ }^{177} \mathrm{Lu}$-Dendrimer-AuNP-FolateBombesin nanoprobe located inside cancer cells. Mol. Imaging 16, 153601211770476. doi:10.1177/1536012117704768

Meng, Q., Li, F., Jiang, S., and Li, Z. (2013). Novel 64Cu-labeled CUDC-101 for in Vivo PET imaging of histone deacetylases. ACS Med. Chem. Lett. 4 (9), 858-862. doi:10.1021/ml400191z

Messori, L., Marzo, T., Michelucci, E., Russo Krauss, I., Navarro-Ranninger, C., Quiroga, A. G., et al. (2014). Interactions between anticancer trans-platinum compounds and proteins: crystal structures and ESI-MS spectra of two protein adducts of trans-(dimethylamino)(methylamino)dichloridoplatinum(II). Inorg. Chem. 53 (15), 7806-7808. doi:10.1021/ic5012583

Miller-Kleinhenz, J. M., Bozeman, E. N., and Yang, L. (2015). Targeted nanoparticles for image-guided treatment of triple-negative breast cancer: clinical significance and technological advances. WIREs Nanomed Nanobiotechnol 7 (6), 797-816. doi:10.1002/wnan.1343

Moores, S. L., Chiu, M. L., Bushey, B. S., Chevalier, K., Luistro, L., Dorn, K., et al. (2016). A novel bispecific antibody targeting EGFR and cMet is effective against EGFR inhibitor-resistant lung tumors. Cancer Res. 76 (13), 3942-3953. doi:10. 1158/0008-5472.can-15-2833

Morgenroth, A., Tinkir, E., Vogg, A. T. J., Sankaranarayanan, R. A., Baazaoui, F., and Mottaghy, F. M. (2019). Targeting of prostate-specific membrane antigen for radio-ligand therapy of triple-negative breast cancer. Breast Cancer Res. 21 (1), 116. doi:10.1186/s13058-019-1205-1

Mukai, H., Saeki, T., Aogi, K., Naito, Y., Matsubara, N., Shigekawa, T., et al. (2016). Patritumab plus trastuzumab and paclitaxel in human epidermal growth factor receptor 2-overexpressing metastatic breast cancer. Cancer Sci. 107 (10), 1465-1470. doi:10.1111/cas.13017

Narmani, A., Yavari, K., and Mohammadnejad, J. (2017). Imaging, biodistribution and in vitro study of smart ${ }^{99 \mathrm{~m}} \mathrm{Tc}$-PAMAM G4 dendrimer as novel nanocomplex. Colloids Surf. B: Biointerfaces 159, 232-240. doi:10.1016/j.colsurfb. 2017.07.089

Nounou, M. I., Adkins, C. E., Rubinchik, E., Terrell-Hall, T. B., Afroz, M., Vitalis, T., et al. (2016). Anti-cancer antibody trastuzumab-melanotransferrin conjugate (BT2111) for the treatment of metastatic HER2+ breast cancer tumors in the brain: an in-vivo study. Pharm. Res. 33 (12), 2930-2942. doi:10.1007/s11095-016-2015-0

O’Donnell, K. A., Yu, D., Zeller, K. I., Kim, J.-w., Racke, F., Thomas-Tikhonenko, A., et al. (2006). Activation of transferrin receptor 1 by c-Myc enhances cellular 
proliferation and tumorigenesis. Mcb 26 (6), 2373-2386. doi:10.1128/MCB.26. 6.2373-2386.2006

O'Sullivan, C. C., Suman, V. J., and Goetz, M. P. (2019). The emerging role of CDK4/6i in HER2-positive breast cancer. Ther. Adv. Med. Oncol. 11, 1758835919887665. doi:10.1177/1758835919887665

Pachynski, R. K., Wang, P., Salazar, N., Zheng, Y., Nease, L., Rosalez, J., et al. (2019). Chemerin suppresses breast cancer growth by recruiting immune effector cells into the tumor microenvironment. Front. Immunol. 10, 983. doi:10.3389/fimmu.2019.00983

Pascual, L., Cerqueira-Coutinho, C., García-Fernández, A., de Luis, B., Bernardes, E. S., Albernaz, M. S., et al. (2017). MUC1 aptamer-capped mesoporous silica nanoparticles for controlled drug delivery and radio-imaging applications. Nanomedicine: Nanotechnology, Biol. Med. 13 (8), 2495-2505. doi:10.1016/j. nano.2017.08.006

Peart, O. (2017). Metastatic breast cancer. Radiol. Technol. 88 (5), 519M-539M.

Perumalsamy, S., Aqilah Mohd Zin, N. A., Widodo, R. T., Wan Ahmad, W. A., Vethakkan, S. R. D. B., and Huri, H. Z. (2017). Chemokine like receptor-1 (CMKLR-1) receptor: a potential therapeutic target in management of chemerin induced type 2 diabetes mellitus and cancer. Cpd 23 (25), 3689-3698. doi:10.2174/1381612823666170616081256

Pishvaian, M., Morse, M. A., McDevitt, J., Norton, J. D., Ren, S., Robbie, G. J., et al. (2016). Phase 1 dose escalation study of MEDI-565, a bispecific T-cell engager that targets human carcinoembryonic antigen, in patients with advanced gastrointestinal adenocarcinomas. Clin. Colorectal Cancer 15 (4), 345-351. doi:10.1016/j.clcc.2016.07.009

Pouget, J.-P., Navarro-Teulon, I., Bardiès, M., Chouin, N., Cartron, G., Pèlegrin, A., et al. (2011). Clinical radioimmunotherapy-the role of radiobiology. Nat. Rev. Clin. Oncol. 8 (12), 720-734. doi:10.1038/nrclinonc.2011.160

Qu, X., Wang, H., and Liu, R. (2018). Recent insights into biological functions of mammalian bombesin-like peptides and their receptors. Curr. Opin. Endocrinol. Diabetes Obes. 25 (1), 36-41. doi:10.1097/MED.0000000000000375

Quadros, E. V., and Sequeira, J. M. (2013). Cellular uptake of cobalamin: transcobalamin and the TCblR/CD320 receptor. Biochimie 95 (5), 1008-1018. doi:10.1016/j.biochi.2013.02.004

Ramos, N., Baquero-Buitrago, J., Ben Youss Gironda, Z., Wadghiri, Y. Z., Reiner, T., Boada, F. E., et al. (2020). Noninvasive PET imaging of CDK4/6 activation in breast cancer. J. Nucl. Med. 61 (3), 437-442. doi:10.2967/jnumed.119.232603

Ranogajec, I., Jakić-Razumović, J., Puzović, V., and Gabrilovac, J. (2012). Prognostic value of matrix metalloproteinase-2 (MMP-2), matrix metalloproteinase-9 (MMP-9) and aminopeptidase N/CD13 in breast cancer patients. Med. Oncol. 29 (2), 561-569. doi:10.1007/s12032-011-9984-y

Reubi, J., Gugger, M., and Waser, B. (2002). Co-expressed peptide receptors in breast cancer as a molecular basis for in vivo multireceptor tumour targeting. Eur. J. Nucl. Med. 29 (7), 855-862. doi:10.1007/s00259-002-0794-5

Roberts, M. J., Bentley, M. D., and Harris, J. M. (2002). Chemistry for peptide and protein PEGylation. Adv. Drug Deliv. Rev. 54 (4), 459-476. doi:10.1016/s0169$409 x(02) 00022-4$

Rolli, M., Fransvea, E., Pilch, J., Saven, A., and Felding-Habermann, B. (2003). Activated integrin $\mathrm{v} 3$ cooperates with metalloproteinase MMP-9 in regulating migration of metastatic breast cancer cells. Proc. Natl. Acad. Sci. 100 (16), 9482-9487. doi:10.1073/pnas.1633689100

Rosenberg, J. E., Bambury, R. M., Van Allen, E. M., Drabkin, H. A., Lara, P. N., Jr., Harzstark, A. L., et al. (2014). A phase II trial of AS1411 (a novel nucleolintargeted DNA aptamer) in metastatic renal cell carcinoma. Invest. New Drugs 32 (1), 178-187. doi:10.1007/s10637-013-0045-6

Ross, J. S., Slodkowska, E. A., Symmans, W. F., Pusztai, L., Ravdin, P. M., and Hortobagyi, G. N. (2009). The HER-2 receptor and breast cancer: ten years of targeted anti-HER-2 therapy and personalized medicine. Oncol. 14 (4), 320-368. doi:10.1634/theoncologist.2008-0230

Ruf, W., Yokota, N., and Schaffner, F. (2010). Tissue factor in cancer progression and angiogenesis. Thromb. Res. 125 (Suppl. 2), S36-S38. doi:10.1016/S00493848(10)70010-4

Salgia, R., Weaver, R. W., McCleod, M., Stille, J. R., Yan, S. B., Roberson, S., et al. (2017). Prognostic and predictive value of circulating tumor cells and CXCR4 expression as biomarkers for a CXCR4 peptide antagonist in combination with carboplatin-etoposide in small cell lung cancer: exploratory analysis of a phase II study. Invest. New Drugs 35 (3), 334-344. doi:10.1007/s10637-017-0446-z
Salvucci, O., Bouchard, A., Baccarelli, A., Deschenes, J., Sauter, G., Simon, R., et al. (2006). The role of CXCR4 receptor expression in breast cancer: a large tissue microarray study. Breast Cancer Res. Treat. 97 (3), 275-283. doi:10.1007/ s10549-005-9121-8

Schafer, K. A. (1998). The cell cycle: a review. Vet. Pathol. 35 (6), 461-478. doi:10. $1177 / 030098589803500601$

Schöffski, P., Cresta, S., Mayer, I. A., Wildiers, H., Damian, S., Gendreau, S., et al. (2018). A phase Ib study of pictilisib (GDC-0941) in combination with paclitaxel, with and without bevacizumab or trastuzumab, and with letrozole in advanced breast cancer. Breast Cancer Res. 20 (1), 109. doi:10. 1186/s13058-018-1015-x

Sergina, N. V., Rausch, M., Wang, D., Blair, J., Hann, B., Shokat, K. M., et al. (2007). Escape from HER-family tyrosine kinase inhibitor therapy by the kinaseinactive HER3. Nature 445 (7126), 437-441. doi:10.1038/nature05474

Shi, S., Hong, H., Orbay, H., Graves, S. A., Yang, Y., Ohman, J. D., et al. (2015). ImmunoPET of tissue factor expression in triple-negative breast cancer with a radiolabeled antibody Fab fragment. Eur. J. Nucl. Med. Mol. Imaging 42 (8), 1295-1303. doi:10.1007/s00259-015-3038-1

Shimizu, T., LoRusso, P. M., Papadopoulos, K. P., Patnaik, A., Beeram, M., Smith, L. S., et al. (2014). Phase I first-in-human study of CUDC-101, a multitargeted inhibitor of HDACs, EGFR, and HER2 in patients with advanced solid tumors. Clin. Cancer Res. 20 (19), 5032-5040. doi:10. 1158/1078-0432.CCR-14-0570

Shin, W. J., and Pachynski, R. K. (2018). Chemerin modulation of tumor growth: potential clinical applications in cancer. Discov. Med. 26 (141), 31-37.

Sijbrandi, N. J., Merkul, E., Muns, J. A., Waalboer, D. C. J., Adamzek, K., Bolijn, M., et al. (2017). A novel platinum(II)-Based bifunctional ADC linker benchmarked using $89 \mathrm{Zr}$-desferal and auristatin F-conjugated trastuzumab. Cancer Res. 77 (2), 257-267. doi:10.1158/0008-5472.CAN-16-1900

Singh, A., Bishayee, A., and Pandey, A. (2018). Targeting histone deacetylases with natural and synthetic agents: an emerging anticancer strategy. Nutrients 10 (6), 731. doi:10.3390/nu10060731

Siroy, A., Abdul-Karim, F. W., Miedler, J., Fong, N., Fu, P., Gilmore, H., et al. (2013). MUC1 is expressed at high frequency in early-stage basal-like triplenegative breast cancer. Hum. Pathol. 44 (10), 2159-2166. doi:10.1016/j. humpath.2013.04.010

Song, X., Gan, Q., Zhang, X., and Zhang, J. (2019). Synthesis and biological evaluation of novel ${ }^{99 \mathrm{~m}} \mathrm{Tc}$-labeled palbociclib derivatives targeting cyclindependent kinase 4/6 (CDK4/6) as potential cancer imaging agents. Mol. Pharmaceutics 16 (10), 4213-4222. doi:10.1021/acs.molpharmaceut.9b00540

Steding, C. E. (2016). Creating chemotherapeutic-resistant breast cancer cell lines: advances and future perspectives. Future Oncol. 12 (12), 1517-1527. doi:10. 2217/fon-2016-0059

Stine, Z. E., Walton, Z. E., Altman, B. J., Hsieh, A. L., and Dang, C. V. (2015). MYC, metabolism, and cancer. Cancer Discov. 5 (10), 1024-1039. doi:10.1158/21598290.CD-15-0507

Sysel, A. M., Valli, V. E., Nagle, R. B., and Bauer, J. A. (2013). Immunohistochemical quantification of the vitamin B12 transport protein (TCII), cell surface receptor (TCII-R) and Ki-67 in human tumor xenografts. Anticancer Res. 33 (10), 4203-4212.

Tang, S., Zhou, F., Sun, Y., Wei, L., Zhu, S., Yang, R., et al. (2016). CEA in breast ductal secretions as a promising biomarker for the diagnosis of breast cancer: a systematic review and meta-analysis. Breast Cancer 23 (6), 813-819. doi:10. 1007/s12282-016-0680-9

Tang, Y., Cui, X., Xiao, H., Qi, S., Hu, X., Yu, Q., et al. (2017). Binding of circulating anti-MUC1 antibody and serum MUC1 antigen in stage IV breast cancer. Mol. Med. Rep. 15 (5), 2659-2664. doi:10.3892/mmr.2017.6323

Tate, C. R., Rhodes, L. V., Segar, H. C., Driver, J. L., Pounder, F. N., Burow, M. E., et al. (2012). Targeting triple-negative breast cancer cells with the histone deacetylase inhibitor panobinostat. Breast Cancer Res. 14 (3), R79. doi:10.1186/ bcr3192

Tejería, E., Giglio, J., Fernández, L., and Rey, A. (2019). Development and evaluation of a ${ }^{99 \mathrm{~m}} \mathrm{Tc}(\mathrm{V})$-nitrido complex derived from estradiol for breast cancer imaging. Appl. Radiat. Isot. 154, 108854. doi:10.1016/j.apradiso.2019. 108854

Thakur, A., Huang, M., and Lum, L. G. (2018). Bispecific antibody based therapeutics: strengths and challenges. Blood Rev. 32 (4), 339-347. doi:10. 1016/j.blre.2018.02.004 
Thakur, M. L., Zhang, K., Berger, A., Cavanaugh, B., Kim, S., Channappa, C., et al. (2013). VPAC1 receptors for imaging breast cancer: a feasibility study. J. Nucl. Med. 54 (7), 1019-1025. doi:10.2967/jnumed.112.114876

Treeck, O., Buechler, C., and Ortmann, O. (2019). Chemerin and cancer. Ijms 20 (15), 3750. doi:10.3390/ijms20153750

Ueno, T., Toi, M., Koike, M., Nakamura, S., and Tominaga, T. (2000). Tissue factor expression in breast cancer tissues: its correlation with prognosis and plasma concentration. Br. J. Cancer 83 (2), 164-170. doi:10.1054/bjoc.2000.1272

Valkema, R., de Jong, M., Bakker, W. H., Breeman, W. A. P., Kooij, P. P. M., Lugtenburg, P. J., et al. (2002). Phase I study of peptide receptor radionuclide therapy with $\left[{ }^{111} \mathrm{In}-\mathrm{DTPA}\right]$ octreotide: the rotterdam experience. Semin. Nucl. Med. 32 (2), 110-122. doi:10.1053/snuc/2002.31025

Vall-Sagarra, A., Litau, S., Decristoforo, C., Wängler, B., Schirrmacher, R., Fricker, G., et al. (2018). Design, synthesis, in vitro, and initial in vivo evaluation of heterobivalent peptidic ligands targeting both NPY(Y1)- and GRP-receptors-an improvement for breast cancer imaging?. Pharmaceuticals 11 (3), 65. doi:10. 3390/ph11030065

Vallböhmer, D., Zhang, W., Gordon, M., Yang, D. Y., Yun, J., Press, O. A., et al. (2005). Molecular determinants of cetuximab efficacy. Jco 23 (15), 3536-3544. doi:10.1200/JCO.2005.09.100

VanArsdale, T., Boshoff, C., Arndt, K. T., and Abraham, R. T. (2015). Molecular pathways: targeting the cyclin D-CDK4/6 Axis for cancer treatment. Clin. Cancer Res. 21 (13), 2905-2910. doi:10.1158/1078-0432.CCR-14-0816

Varasteh, Z., Rosenström, U., Velikyan, I., Mitran, B., Altai, M., Honarvar, H., et al. (2014). The effect of mini-PEG-based spacer length on binding and pharmacokinetic properties of a ${ }^{68} \mathrm{Ga}$-labeled NOTA-conjugated antagonistic analog of bombesin. Molecules 19 (7), 10455-10472. doi:10. 3390/molecules 190710455

Viola-Villegas, N., and Doyle, R. P. (2009). The coordination chemistry of 1,4,7,10tetraazacyclododecane- $\mathrm{N}, \mathrm{N}^{\prime}, \mathrm{N}^{\prime \prime}, \mathrm{N}^{\prime \prime \prime}$-tetraacetic acid (H4DOTA): structural overview and analyses on structure-stability relationships. Coord. Chem. Rev. 253 (13-14), 1906-1925. doi:10.1016/j.ccr.2009.03.013

Waaijer, S. J. H., Warnders, F. J., Stienen, S., Friedrich, M., Sternjak, A., Cheung, H. K., et al. (2018). Molecular imaging of radiolabeled bispecific T-cell engager ${ }^{89}$ Zr-AMG211 targeting CEA-positive tumors. Clin. Cancer Res. 24 (20), 4988-4996. doi:10.1158/1078-0432.Ccr-18-0786

Waks, A. G., and Winer, E. P. (2019). Breast cancer treatment. JAMA 321 (3), 288-300. doi:10.1001/jama.2018.19323

Wang, B., Guo, C., Liu, Y., Han, G., Li, Y., Zhang, Y., et al. (2020). Novel nanopomegranates based on astragalus polysaccharides for targeting ERa-positive breast cancer and multidrug resistance. Drug Deliv. 27 (1), 607-621. doi:10. 1080/10717544.2020.1754529

Wang, B., Rouzier, R., Albarracin, C. T., Sahin, A., Wagner, P., Yang, Y., et al. (2004). Expression of sigma 1 receptor in human breast cancer. Breast Cancer Res. Treat. 87 (3), 205-214. doi:10.1007/s10549-004-6590-0

Wang, W., Xu, X., Tian, B., Wang, Y., Du, L., Sun, T., et al. (2017). The diagnostic value of serum tumor markers CEA, CA19-9, CA125, CA15-3, and TPS in metastatic breast cancer. Clinica Chim. Acta 470, 51-55. doi:10.1016/j.cca.2017. 04.023

Wang, Z. (2017). ErbB receptors and cancer. Methods Mol. Biol. 1652, 3-35. doi:10. 1007/978-1-4939-7219-7_1
Xia, X., Feng, H., Li, C., Qin, C., Song, Y., Zhang, Y., et al. (2016). ${ }^{99 m}$ Tc-labeled estradiol as an estrogen receptor probe: preparation and preclinical evaluation. Nucl. Med. Biol. 43 (1), 89-96. doi:10.1016/j.nucmedbio.2015.09.006

$\mathrm{Xu}, \mathrm{C}$., Zhao, H., Chen, H., and Yao, Q. (2015). CXCR4 in breast cancer: oncogenic role and therapeutic targeting. Drug Des. Devel Ther. 9, 4953-4964. doi:10.2147/ DDDT.S84932

Yamamoto, N., Fujiwara, Y., Tamura, K., Kondo, S., Iwasa, S., Tanabe, Y., et al. (2017). Phase Ia/Ib study of the pan-class I PI3K inhibitor pictilisib (GDC0941) administered as a single agent in Japanese patients with solid tumors and in combination in Japanese patients with non-squamous non-small cell lung cancer. Invest. New Drugs 35 (1), 37-46. doi:10.1007/s10637-016-0382-3

Yang, S. P., Song, S. T., and Song, H. F. (2003). Advancements of antisense oligonucleotides in treatment of breast cancer. Acta Pharmacol. Sin 24 (4), 289-295.

Yook, S., Cai, Z., Jeong, J. J., Lu, Y., Winnik, M. A., Pignol, J.-P., et al. (2020). Dualreceptor-targeted (DRT) radiation nanomedicine labeled with ${ }^{177} \mathrm{Lu}$ is more potent for killing human breast cancer cells that coexpress HER2 and EGFR than single-receptor-targeted (SRT) radiation nanomedicines. Mol. Pharmaceutics 17 (4), 1226-1236. doi:10.1021/acs.molpharmaceut.9b01259

Zhang, C.-X., Zhang, Q., Xie, Y.-Y., He, X.-Y., Xiang, C., Hou, X.-S., et al. (2017). Mouse double minute 2 actively suppresses p53 activity in oocytes during mouse folliculogenesis. Am. J. Pathol. 187 (2), 339-351. doi:10.1016/j.ajpath. 2016.09.023

Zhang, J. Y., Mai, G. F., Zheng, H., Luo, R. C., Song, H. Z., Miao, J. X., et al. (2003). [Association between the survival time and high-expression of EGFR and HER2 in breast cancer]. Di Yi Jun Yi Da Xue Xue Bao 23 (10), 1090-1092.

Zhang, X., You, L., Chen, S., Gao, M., Guo, Z., Du, J., et al. (2018). Development of a novel ${ }^{99 \mathrm{~m}} \mathrm{Tc}$-labeled small molecular antagonist for CXCR4 positive tumor imaging. J. Label Compd. Radiopharm. 61 (5), 438-446. doi:10.1002/jlcr.3608

Zhang, Z., Ni, C., Chen, W., Wu, P., Wang, Z., Yin, J., et al. (2014a). Expression of CXCR4 and breast cancer prognosis: a systematic review and meta-analysis. BMC Cancer 14, 49. doi:10.1186/1471-2407-14-49

Zhang, Z., Wang, J., Tacha, D. E., Li, P., Bremer, R. E., Chen, H., et al. (2014b). Folate receptor a associated with triple-negative breast cancer and poor prognosis. Arch. Pathol. Lab. Med. 138 (7), 890-895. doi:10.5858/arpa.20130309-OA

Zolata, H., Abbasi Davani, F., and Afarideh, H. (2015). Synthesis, characterization and theranostic evaluation of Indium-111 labeled multifunctional superparamagnetic iron oxide nanoparticles. Nucl. Med. Biol. 42 (2), 164-170. doi:10.1016/j.nucmedbio.2014.09.007

Conflict of Interest: The authors declare that the research was conducted in the absence of any commercial or financial relationships that could be construed as a potential conflict of interest.

Copyright (c) 2021 Fang, Cavaliere, Li, Huang and Marquez-Nostra. This is an openaccess article distributed under the terms of the Creative Commons Attribution License (CC BY). The use, distribution or reproduction in other forums is permitted, provided the original author(s) and the copyright owner(s) are credited and that the original publication in this journal is cited, in accordance with accepted academic practice. No use, distribution or reproduction is permitted which does not comply with these terms. 